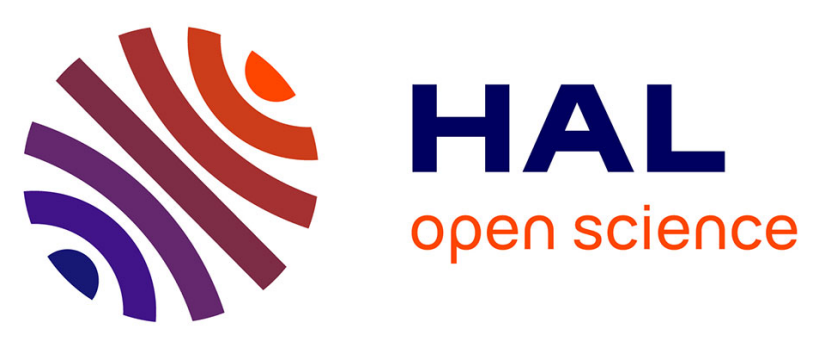

\title{
Study of $\mathrm{CuO}-\mathrm{CeO} 2$ catalysts supported on ordered porous silica with different mesostructure and morphology. Influence on CO preferential oxidation
}

Albano M. Lacoste, Inés S. Tiscornia, Magali Bonne, Laure Michelin, Bénédicte Lebeau, Alicia V. Boix

\section{To cite this version:}

Albano M. Lacoste, Inés S. Tiscornia, Magali Bonne, Laure Michelin, Bénédicte Lebeau, et al.. Study of $\mathrm{CuO}-\mathrm{CeO} 2$ catalysts supported on ordered porous silica with different mesostructure and morphology. Influence on CO preferential oxidation. Microporous and Mesoporous Materials, 2021, 320, pp.111094. 10.1016/j.micromeso.2021.111094 . hal-03206117

\section{HAL Id: hal-03206117 https://hal.science/hal-03206117}

Submitted on 22 Apr 2021

HAL is a multi-disciplinary open access archive for the deposit and dissemination of scientific research documents, whether they are published or not. The documents may come from teaching and research institutions in France or abroad, or from public or private research centers.
L'archive ouverte pluridisciplinaire HAL, est destinée au dépôt et à la diffusion de documents scientifiques de niveau recherche, publiés ou non, émanant des établissements d'enseignement et de recherche français ou étrangers, des laboratoires publics ou privés. 


\title{
Study of $\mathrm{CuO}-\mathrm{CeO}_{2}$ catalysts supported on ordered porous silica with different mesostructure and morphology. Influence on CO preferential oxidation.
}

Albano M. Lacoste ${ }^{\mathrm{a}}$, Inés S. Tiscornia*, Magali Bonne ${ }^{\mathrm{b}, \mathrm{c}}$, Laure Michelin ${ }^{\mathrm{b}, \mathrm{c}}$, Bénédicte Lebeau $^{\mathrm{b}, \mathrm{c}}$, Alicia V. Boix ${ }^{\mathrm{a}}$

${ }^{a}$ Instituto de Investigaciones en Catálisis y Petroquímica, INCAPE (FIQ, UNL-CONICET), 3000 Santa Fe, Argentina.

${ }^{b}$ Université de Haute Alsace (UHA), CNRS, IS2M UMR 7361, 68100 Mulhouse, France.

${ }^{c}$ Université de Strasbourg, F-67000 Strasbourg, France.

${ }^{*}$ Contact author information: Inés S. Tiscornia

e-mail: itiscornia@fiq.unl.edu.ar

Full postal address: INCAPE. Santiago del Estero 2829 - (3000) Santa Fe, Argentina

Phone number: +54-342-4536861

Submitted to: Microporous and Mesoporous Materials

\begin{abstract}
In the present work, SBA-15 and SBA-16 ordered mesoporous silicas were synthesized with different morphologies such as fibers, spheres, rods and irregular shapes. Copper and cerium oxides active phase was introduced by two methods, incipient wetness impregnation and solid-state impregnation by using a ball mill. The obtained catalysts were evaluated in the
\end{abstract}


CO preferential oxidation reaction (COPrOx). By means of SAXS, XRD, SEM and TEM microscopies, the mesostructures and morphologies were characterized, as well as the preservation of the porous structure and the presence of oxides nanoparticles. In addition, XPS spectroscopy was used to analyze the chemical state and relative surface abundance of the elements present in the catalysts. From the catalytic results, it could be seen that the incipient wetness impregnation method was the most favorable. The unidirectional porous structure SBA-15 with fiber shape and incipient wetness impregnation achieved the highest conversion of $\mathrm{CO}$ and selectivity to $\mathrm{CO}_{2}\left(\mathrm{CO}\right.$ conversion $98 \%$ at $\left.175{ }^{\circ} \mathrm{C}\right)$. SBA-16 based catalysts were found less active. However, it is noteworthy that the best material was prepared by using an irregular shaped SBA-16 impregnated by incipient wetness procedure. This catalyst exhibited a maximum CO conversion of $80 \%$ at $175{ }^{\circ} \mathrm{C}$. Finally, the SBA- 15 mesoporous structure and the incipient wetness impregnation method had a greater influence on the better catalytic performance.

Keywords: SBA-15 and SBA-16, particle morphology, $\mathrm{COPrOx}, \mathrm{CuO}-\mathrm{CeO}_{2}$ nanoparticles, active phase incorporation. 


\section{Introduction}

The preferential oxidation of $\mathrm{CO}(\mathrm{COPrOx})$ reaction has been deeply studied in the last years because it represents an inexpensive and practical method to purify the $\mathrm{H}_{2}$ that is fed to the proton exchange membrane (PEM) fuel cells. Nowadays, the main way to produce this hydrogen is by means of steam reforming or autothermal reforming of hydrocarbons and alcohols. Usually, this step is followed by the Water Gas Shift (WGS) reaction, where the stream is enriched in hydrogen. However, the effluent contains around $1 \% \mathrm{CO}$ and it must be further purified to prevent the cell anode from poisoning. COPrOx has been demonstrated to be a suitable reaction that selectively oxidizes $\mathrm{CO}$ to obtain high-purity $\mathrm{H}_{2}$ in a wide operation temperature interval $\left(80-180{ }^{\circ} \mathrm{C}\right)$ for practical application in fuel cells [1]. Numerous catalytic systems such as noble metal ( $\mathrm{Au}, \mathrm{Pt}, \mathrm{Rh}$, etc.) supported on different carriers [2,3], bimetallic systems [4] and mixed transition metal oxides [5] have been studied for total and preferential $\mathrm{CO}$ oxidation. In particular, ceria is among the most commonly used reducible oxides in oxidation reactions due to its high oxygen storage capacity and its ability to effectively supply oxygen to active centers. In this way, $\mathrm{CeO}_{2}$ acts as an oxygen transporter, whose mobility is favored by the ease of alternating between the two oxidation states $\mathrm{Ce}^{3+} / \mathrm{Ce}^{4+}$ at the surface level. As reported by the literature, when combined with precious or transition metals these remarkable redox properties can be improved due to a synergic effect linked to metal-support interactions [6-8]. In particular, $\mathrm{CuO}_{\mathrm{x}}-\mathrm{CeO}_{2}$ and $\mathrm{CoO}_{\mathrm{x}}-\mathrm{CeO}_{2}$ catalytic systems have been explored for their utility in a diversity of environmental and energy applications such as water-gas-shift (WGS) reaction, volatile organic compounds (VOCs) oxidation, low-temperature $\mathrm{CO}$ oxidation (COTOx) and CO selective oxidation in rich hydrogen streams (COPrOx) $[9,10,19,11-18]$. 
The $\mathrm{CuO}-\mathrm{CeO}_{2}$ system has been tested and showed high activity, selectivity and durability for the COPrOx [20]. The Mars van Krevelen mechanism has been proposed for this type of oxide-based catalysts when used in CO oxidation reaction [21-23]. According to this mechanism, $\mathrm{CO}$ molecules are adsorbed over $\mathrm{Cu}$ ions active sites and therefore activated. Then the $\mathrm{Cu}$ ions- $\mathrm{CO}$ species react with the active oxygen species on the surface over $\mathrm{Cu}-\mathrm{Ce}$ oxides forming $\mathrm{CO}_{2}$ and leaving an oxygen vacancy. Finally, the gas-phase provides the oxygen necessary to replenish these vacancies._In addition, the interactions between metal oxides $(\mathrm{Cu}$ and $\mathrm{Ce})$ have a key role in the catalytic performance for COPrOx. Some studies have shown that it is possible to improve the catalytic behavior of these materials by changing the geometric type of interactions between copper oxide and ceria (e.g., by employing different morphology of ceria particles, inverse configurations, etc.) [24-27]. In order to improve the activity and stability of the catalysts, several materials were used as support of the $\mathrm{CuO}-\mathrm{CeO}_{2}$ active phase. Aguila et al. [28] tested this system over various supports in low-temperature $\mathrm{CO}$ oxidation and they observed that the deposition of the active metal oxides on different materials affected the interaction between $\mathrm{Cu}$ and $\mathrm{Ce}$ species, being the $\mathrm{SiO}_{2}$ the better alternative. Different silica-based materials were used as supports for the $\mathrm{CuO}-\mathrm{CeO}_{2}$ system in $\mathrm{COTOx}$ and $\mathrm{COPrOx}$ reactions [29-32]. In this vein, ordered mesoporous silicas such as SBA-15 have proven to be adequate catalytic supports. This material has a bi-dimensional structure of parallel mesopores that allows the deposition of active phase nanoparticles. Similarly, SBA-16 is a mesoporous silica from the same family which has been significantly less studied as catalysts support. Unlike SBA-15, SBA-16 has a three-dimensional configuration in which each cage-type mesopore is connected to eight surrounding cage-type mesopores. Both SBA-15 and SBA-16 porous structures provide these materials with high specific surface area, pore volumes and stability. In addition, they have 
the advantage that these properties, among others (morphology, pore diameter, surface silanols, etc.), can be tuned with careful control of the synthesis conditions.

Many authors studied the formation mechanisms of SBA-15 and SBA-16 particles [33-37], they suggested a colloidal phase separation mechanism in which the separation of liquid crystal-like phase from the solution and posterior condensation of silica species is a critical stage in the final particle shape and dimensions. Because of this, changing synthesis parameters in the initial steps (ripening) of SBA-15 and SBA-16 has the most influence on the morphology which might be desired in some applications. For example, intending to explore the inherent factors that determine the activity of supported Ag catalysts in $\mathrm{CO}$ oxidation, $\mathrm{Xu}$ et al. [38] tested a series of mesoporous $\mathrm{SiO}_{2}$ with different morphologies as supports. They found that the morphologies of the $\mathrm{SiO}_{2}$ supports influenced the dispersion of the supported Ag species, resulting in catalysts with different active metallic Ag surface areas. Studying other applications, Jin et al. [39] observed that marked differences in ibuprofen release behavior of stick and plate-like SBA-15. Cao et al. [40] tested NiMo catalysts supported over five Al-SBA-16 materials with different morphology for dibenzothiophene hydrodesulfurization. Despite the fact that they reported differences in conversions among the tested materials, they did not find a direct relation between conversion and particle shape. On the other hand, the morphology and the size of the particles can be key factors in the preparation of structured catalysts [41-44]. In our previous work [45], $\mathrm{CuO}-\mathrm{CeO}_{2} / \mathrm{SiO}_{2}$ powders were coated on monoliths, where $\mathrm{SiO}_{2}$ supports were SBA-15 (fibers), aerosil (agglomerated nano-spheres) and celite (irregular micro-particles). The deposited films showed differences regarding mechanical resistance, where the packing and thickness of the layer also influenced the catalytic behavior. 
To incorporate metal oxide precursors into mesoporous materials, incipient wetness impregnation is one of the most widespread methods for its simplicity and because it ensures that practically all the active phase is located inside the mesopores. However, various authors have reported materials based on SBA-15 in which it is possible to obtain a good dispersion of the active material incorporating it via "solid impregnation" [31,46-48]. For example, Tang et al. [31] synthesized catalysts $\mathrm{CuO}-\mathrm{CeO}_{2} / \mathrm{SBA}-15$ using the solid impregnation and wet impregnation methods and found better catalytic results for the first alternative. Although these materials have been tested for various applications, a straightforward comparison of $\mathrm{CuO}-\mathrm{CeO}_{2}$ supported on ordered mesoporous silicas with different mesostructures and morphologies has not been addressed.

For this reason, the aim of this work is to investigate the catalytic behavior in COPrOx reaction of the $\mathrm{CuO}-\mathrm{CeO}_{2}$ system supported on SBA-15 and SBA-16 with different morphologies and to explore the differences between two impregnation methods. In consequence, synthesis parameters of the mesoporous silica supports were modified with the objective of obtaining diverse morphologies (fibers, rods, spheres, etc.). The catalysts were prepared by solid-state impregnation and incipient wetness impregnation methods. The resulting solids were tested in COPrOx reaction and characterized by several techniques. SEM-EDS and TEM were used to analyze the morphology and structure of catalysts. In addition, the textural properties, specific surface area, pore volume and pore size distribution were evaluated from $\mathrm{N}_{2}$ adsorption-desorption isotherms at $77 \mathrm{~K}$. The mesoporous structure and the crystalline phases were studied by small-angle X-ray scattering (SAXS) and XRD, respectively. X-ray Photoelectron Spectroscopy (XPS) analyses were performed in a multi- 
technique system, and the chemical state and relative abundance of copper and cerium species on the surface were also studied.

\section{Experimental}

\subsection{Materials}

SBA-15 and SBA-16 mesoporous supports were synthesized using triblock polymers Pluronic P123 $\left(\mathrm{EO}_{20}-\mathrm{PO}_{70}-\mathrm{EO}_{20}\right.$, average $\left.\mathrm{Mn} \sim 5800 \mathrm{~g} \mathrm{~mol}^{-1}\right)$ or Pluronic F127 $\left(\mathrm{EO}_{106}-\mathrm{PO}_{70}-\right.$ $\mathrm{EO}_{106}$, average $\mathrm{Mn} \sim 12600 \mathrm{~g} \mathrm{~mol}^{-1}$ ) from Sigma-Aldrich ${ }^{\circledR}$ as structure-directing agents. Tetraethyl orthosilicate (TEOS, reagent grade, $98 \%$, Sigma-Aldrich ${ }^{\circledR}$ ) was used as the silica source. Aqueous chlorhydric acid solution (36.5-38 \%, Cicarelli $\left.{ }^{\circledR}\right)$ was employed to adjust the medium pH. In one of the syntheses of SBA-16, n-butanol $\left(\mathrm{C}_{4} \mathrm{H}_{9} \mathrm{OH}\right.$, p. a., $99.5 \%$, Cicarelli $\left.{ }^{\circledR}\right)$ was added as co-surfactant. In addition, cerium nitrate $\left(\mathrm{Ce}\left(\mathrm{NO}_{3}\right)_{3} \cdot 6 \mathrm{H}_{2} \mathrm{O}, 99 \%\right)$ and copper nitrate $\left(\mathrm{Cu}\left(\mathrm{NO}_{3}\right)_{2} \cdot 3 \mathrm{H}_{2} \mathrm{O}\right.$, p.a. $)$ from Sigma-Aldrich ${ }^{\circledR}$ were selected as precursors salts. Ethanol $(99.5 \%)$ from Cicarelli ${ }^{\circledR}$ was used as solvent in the incipient wetness impregnation method.

\subsection{Mesoporous supports syntheses}

Usually, the synthesis of SBA-15 and SBA-16 consists in the dissolution of the structuredirecting agent in the solvent (this step also includes adjustment $\mathrm{pH}$, temperature, addition of co-solvents, etc.) followed by the addition of the silica source. After the ripening and ageing steps (where the hydrolysis, pre-condensation, and condensation processes take place) the products are recovered, washed and dried. Finally, the template is removed from the structure. 


\subsubsection{SBA-15}

Two SBA-15 solids with different morphology were obtained by a typical synthesis method changing experimental parameters in some stages [49]. In the first synthesis, $2 \mathrm{~g}$ of surfactant Pluronic ${ }^{\circledR} \mathrm{P} 123$ was added to the acidic solution of $65 \mathrm{~g} \mathrm{H}_{2} \mathrm{O}$ deionized and $11.9 \mathrm{~g} \mathrm{HCl}$. The mixture was stirred until complete dissolution and then $4.3 \mathrm{~g}$ of silica source TEOS was added. The solution was heated at $45^{\circ} \mathrm{C}$ and stirred for $7.5 \mathrm{~h}$. Subsequently, the mixture was aged in an oven at $80{ }^{\circ} \mathrm{C}$ for $15.5 \mathrm{~h}$.

A similar SBA-15 synthesis procedure to the above described with some changes in physical variables was followed. In particular, TEOS was added drop by drop and the ripening stage was carried out under static conditions. The obtained solids were recovered by filtration, washed with deionized water and dried at $45{ }^{\circ} \mathrm{C}$ for $24 \mathrm{~h}$. Finally, they were calcined in air for $6 \mathrm{~h}$ at $550{ }^{\circ} \mathrm{C}$ in a muffle furnace to remove the surfactant from the pores. The heating ramp was $1.5^{\circ} \mathrm{C} \min ^{-1}$.

The solids obtained from these syntheses were labeled as 15-M where "M" refers to their morphology.

\subsubsection{SBA-16}

Two synthesis protocols were carried out. On the one hand, the synthesis of Stevens et al. was adapted [35]. First, $1.3 \mathrm{~g}$ of Pluronic ${ }^{\circledR}$ F127 and $4 \mathrm{~g}$ of n-butanol (co-surfactant) were added to $65 \mathrm{~g} \mathrm{H}_{2} \mathrm{O}$ and $2.8 \mathrm{~g} \mathrm{HCl}$ (acidic medium). After completing the $\mathrm{F} 127$ dissolution, $6.7 \mathrm{~g}$ of TEOS was added, and the mixture was stirred at $45^{\circ} \mathrm{C}$ for $24 \mathrm{~h}$. Then, the mixture was transferred to an autoclave and aged in an oven at $100{ }^{\circ} \mathrm{C}$ for $24 \mathrm{~h}$. 
On the other hand, a synthesis without co-surfactant and with one-step ripening and ageing process was performed. A solution was prepared with $1.4 \mathrm{~g}$ of $\mathrm{F} 127,100 \mathrm{~g} \mathrm{H}_{2} \mathrm{O}$ and $17.8 \mathrm{~g}$ $\mathrm{HCl}$ and was immersed in a water bath to $60^{\circ} \mathrm{C}$ and stirred until complete $\mathrm{F} 127$ dissolution. Then, $6.7 \mathrm{~g}$ of TEOS was added drop by drop. The ripening-ageing stage was carried out in an oven at $80^{\circ} \mathrm{C}$ for $24 \mathrm{~h}$ in quiescent conditions. The same last steps as SBA-15 procedures were followed to obtain the final materials (filtration, washing and calcination processes). The solids obtained from these syntheses were identified as $16-\mathrm{M}$ where " $\mathrm{M}$ " refers to their morphology.

\subsection{Catalysts preparation}

The catalysts were prepared with $4.8 \%$ wt. of $\mathrm{CuO}$ and $18.7 \%$ wt. of $\mathrm{CeO}_{2}$ (molar ratio $\mathrm{CuO} / \mathrm{CeO}_{2}=0.55$ ), accordingly to our previous work [50] where the molar ratio of metal oxides was optimized for $\mathrm{CuO}-\mathrm{CeO}_{2} / \mathrm{SBA}-15$ catalysts. The amount of precursor salts was adjusted in order to obtain solids with the desired concentration.

The chemical composition of the powders was measured by X-ray Fluorescence technique, using an XRF spectrometer Shimadzu model EDX-720.

The active phase was introduced by two impregnation methods:

Incipient wetness co-impregnation (WI). In this case, a solution of both copper and cerium nitrates in ethanol was prepared to introduce the precursors by the incipient wetness method in a single-step operation. The wet mixture of mesoporous silica and the mentioned solution was mixed for 5 minutes to achieve its homogenization. The materials were dried at $45{ }^{\circ} \mathrm{C}$ overnight and then calcined at $450{ }^{\circ} \mathrm{C}$ under air flow with a heating ramp of $3.0{ }^{\circ} \mathrm{C} \mathrm{min}^{-1}$ in order to ensure the complete removal of nitrates. It is noteworthy that the calcination 
temperature is above $\mathrm{COPrOx}$ reaction temperatures, which should allow working with a structurally stable material.

Solid-state impregnation by ball milling (BM). Firstly, the precursor salts were manually ground in a ceramic mortar in order to reduce and homogenize the size of the initial crystals. Then, the appropriate amounts of salts and support were mixed and ground by means of a mechanical mill (Mini Mill PHILIPS) made of two zirconium oxide vessels. Samples were placed in the vessels, in the presence of two balls of $10 \mathrm{~g}$ zirconium oxide, which rotated in opposite direction to the rotating wheel of the mill direction. The rotation speed was set to $2600 \mathrm{rpm}$ and the milling time was two times $15 \mathrm{~min}$. After this step, the solids were calcined in the same conditions as the WI method.

In order to identify the method of impregnation, the letters WI or BM were added at the end of the names of the supports. In summary, the catalysts were labeled as $15-\mathrm{M} / \mathrm{WI}$ or $15-$ $\mathrm{M} / \mathrm{BM}$ for mesoporous structure SBA-15 and 16-M/WI or 16-M/BM for structure SBA-16, where "M" refers to its morphology (F: fibers, R: rods, I: irregular or S: spheres).

\subsection{Characterization techniques}

Scanning Electron Microscopy (SEM) and Energy Dispersive Spectrometry (EDS)

Images of the catalysts and supports were obtained using a PhenomProX scanning electron microscope (operated at $15 \mathrm{kV}$ ). EDS analyses were performed employing a fully integrated detector and software of the aforementioned microscope. A second microscope JEOL model JSM-7900F was used for additional analyses, element X-ray mappings were collected with 
a BRUKER QUANTAX EDS. In order to minimize the excitation volume and increase spatial resolution of these maps, a low electron beam energy $(5 \mathrm{kV})$ was applied.

\section{Transmission Electron Microscopy (TEM)}

Materials micrographs were collected on a Philips CM200 microscope equipped with a $\mathrm{LaB}_{6}$ filament. The accelerating voltage was $200 \mathrm{kV}$. Transmission Electron Microscopy (TEM JEM-2100 plus, JEOL) was used to examine the size distribution and morphology of nanoparticles. Samples were previously dispersed in water and immersed in an ultrasonic bath for $10 \mathrm{~min}$. Then, five to ten drops of the solution were deposited onto $\mathrm{Cu}$ grids coated with a thin ( $5 \mathrm{~nm}$ thick) holey carbon support film.

\section{Textural properties}

Nitrogen adsorption-desorption isotherms were recorded at liquid-nitrogen temperature (77 K) in a Micromeritics ASAP 2020 equipment. Before the adsorption, samples were degassed at $170-200{ }^{\circ} \mathrm{C}$ for $8 \mathrm{~h}$. The BET model was used to calculate the total specific surface area. The total pore volume was measured at the $\mathrm{P} / \mathrm{P}^{0}=0.97$ single point. The pore size distribution (PSD) was evaluated employing two methods: the BJH (Barret, Joyner and Halenda) method modified by Kruk, Jaroniec and Sayari (BJH-KJS) [51] and the Density Functional Theory (DFT) model, considering $\mathrm{N}_{2}$ at $77 \mathrm{~K}$, cylindrical pore and adsorption branch data [52].

\section{Small-angle X-ray scattering (SAXS)}

The as-synthesized supports and powder catalysts were characterized by small-angle X-ray scattering (SAXS) on a SAXSess $\mathrm{mc}^{2}$ instrument (Anton Paar), using a line collimation 
system. This instrument is attached to an ID 3003 laboratory X-Ray generator (General Electric) equipped with a sealed X-Ray tube (PANalytical, $\lambda_{\mathrm{Cu}, \mathrm{K} \alpha}=0.1542 \mathrm{~nm}$ ).

$X$-ray diffraction $(X R D)$

X-ray powder diffraction patterns were collected on a Shimadzu XD-D1 with monochromatic $\mathrm{Cu}-\mathrm{K} \alpha$ radiation and a Ni filter at a scanning rate of $2^{\circ} \min ^{-1}$ in $2 \theta=10-70^{\circ}$. The observed diffraction peaks were compared to standards published by JCPDS data (Joint Committee on Powder Diffraction Standards). The crystallite size was estimated by Scherrer's equation.

$X$-ray photoelectron spectroscopy (XPS)

The XPS analyses were performed in a multi-technique system (SPECS) equipped with a dual Mg/Al X-rays source, and a hemispherical PHOIBOS 150 analyzer operating in the fixed analyzer transmission (FAT) mode. The spectra were obtained using a pass energy of $30 \mathrm{eV}$ and the X-ray source was operated at $200 \mathrm{~W}$ and $12 \mathrm{kV}$. The working pressure in the main chamber was less than $2 \times 10-6 \mathrm{~Pa}$. For the quantitative analysis, the regions corresponding to $\mathrm{Ce} 3 \mathrm{~d}, \mathrm{Cu} 2 \mathrm{p}, \mathrm{C} 1 \mathrm{~s}, \mathrm{O} 1 \mathrm{~s}$ and $\mathrm{Si} 2 \mathrm{p}$ core levels were recorded for each sample. The binding energy (B.E.) of the $\mathrm{Si} 2 \mathrm{p}$ signal at $103.4 \mathrm{eV}$ was taken as an internal reference.

The data treatment was performed with the Casa XPS program (Casa Software Ltd, UK). The peaks were considered a mixture of Gaussian and Lorentzian functions. For the quantification of the different elements, sensitivity factors provided by the manufacturer were employed. 


\subsection{Catalytic tests}

The $\mathrm{CO}$ oxidation in the $\mathrm{H}_{2}$-rich stream was evaluated at atmospheric pressure in a fixed bed reactor (quartz tube, i.d. $=15.6 \mathrm{~mm}$ ). The reaction mixture consisted of $\mathrm{CO} 1 \mathrm{vol} \%, \mathrm{O}_{2} 1 \mathrm{vol}$ $\%$ and $\mathrm{H}_{2} 40$ vol \%, He balance. For each test, approximately $0.2 \mathrm{~g}$ of powder sample were loaded in the reactor. The W/F was $2.3 \mathrm{mg}_{\text {cat }}$ min $\mathrm{mL}^{-1}$ (STP) (contact time $\tau=0.138 \mathrm{~g}_{\text {cat }} \mathrm{S}$ $\mathrm{mL}^{-1} \mathrm{STP}$ ), and the temperature was varied from 125 to $225^{\circ} \mathrm{C}$. The measurements were performed after achieving the steady-state, the catalysts were tested for approximately one hour at each temperature point. After evaluation in the whole temperature range, the best conversion and selectivity values were verified with new measurements.

The $\mathrm{CO}$ conversion and the oxygen selectivity towards $\mathrm{CO}_{2}$ were defined according to Equation (1), and Equation (2), respectively:

$$
\begin{aligned}
& X_{\mathrm{CO}}(\%)=\frac{[\mathrm{CO}]^{0}-[\mathrm{CO}]}{[\mathrm{CO}]^{0}} 100 \\
& S_{\mathrm{CO}_{2}}(\%)=0.5 \frac{[\mathrm{CO}]^{0}-[\mathrm{CO}]}{\left[\mathrm{O}_{2}\right]^{0}-\left[\mathrm{O}_{2}\right]} 100
\end{aligned}
$$

where $[\mathrm{CO}]$ and $\left[\mathrm{O}_{2}\right]$ were reactor exit concentrations and $[\mathrm{CO}]^{\circ},\left[\mathrm{O}_{2}\right]^{\circ}$ represented feed concentrations, which were measured using a Shimadzu chromatograph GC-2014 with a thermal conductivity detector (TCD) equipped with a 5A molecular sieve column. The methane formation was negligible at temperatures below $250{ }^{\circ} \mathrm{C}$ under our reaction conditions. The mass balance was closed within $\pm 4 \%$.

\section{Results and Discussion}


In a typical synthesis of SBA-15, the P123 micelles in the acidic solution are spherical. When the silica species begin to interact with them and condense the micelles begin to grow and become elongated, favoring the rod morphology. However, fibers are obtained as the result of the micelles alignment due to the shear force produced by the stirring. The cylindrical micelles merge while the silica condensation continues, resulting in aggregates of long fibers [9,53]. As it can be observed from the SEM micrographs (Figures 1 A and B), SBA-15 with two main morphologies (fibers and rods) was obtained as a result of performing the ripening process under agitation or quiescent conditions. Agglomerates composed of long fibers (labeled as 15-F) are cross-linked with length around 30-40 $\mu \mathrm{m}$ and thickness of $5 \mu \mathrm{m}$ were obtained when ripening was carried out under agitation (Figure $1 \mathrm{~A}$ ). On the other hand, the material synthesized under static condition $(15-\mathrm{R})$ presented mainly short rod particles and the presence of some silica particles without defined shape (presumably not mesoporous), together with rod-shaped particles, which have a length of up to $1 \mu \mathrm{m}$ and thicknesses around $200 \mathrm{~nm}$ (Figure $1 \mathrm{~B})$.

Regarding to SBA-16 materials, Figure $1 \mathrm{C}$ shows the micrograph of the product of the synthesis with butanol (labeled as 16-I). The image revealed irregularly shaped fragments with a wide range of particle sizes $(2-30 \mu \mathrm{m})$. It is known that the low condensation rate of the inorganic species tends to generate spherical particles since this geometry is energetically favored. However, the amount of added silica source can affect the morphology of the synthesized SBA-16. As long as the amount of TEOS is sufficient, the micrometric particles can agglomerate and form macrospheres. Nonetheless, if the amount of TEOS in the reaction mixture is not enough to complete the agglomeration, irregularly shaped particles are obtained instead. Stevens et al. [35] studied the formation of SBA-16 spheres, they observed 
that the amount of added TEOS controlled the size of the resulting spheres with diameters from $4 \mu \mathrm{m}$ to $16 \mathrm{~mm}$. On the other hand, the use of butanol in this procedure allows to obtain the cubic $\operatorname{Im} 3 m$ mesophase in a wider range of concentration of precursors enabling the tuning of pore volume, wall thickness and mesopore size. Since $\mathrm{HCl}$ acts as a catalyst for the reaction, the low acid concentration is important to keep a slow silica condensation rate. In this way the reaction is almost thermodynamically controlled, enabling the butanol to participate as a structure-directing agent [54].

Figure $1 \mathrm{D}$ exhibits the spherical morphology of the particles obtained from the SBA-16 synthesis without co-surfactant (16-S), showing homogeneity in their diameter which varies between 2 and $5 \mu \mathrm{m}$. Typically, according to the colloidal phase separation mechanisms, a competition between the free energy of mesostructure self-assembly and the colloidal surface energy occurs. For this reason, low acidity and low temperatures, among other variables, are important to reduce the condensation rate of the silica species and minimize the surface free energy, obtaining sphere-shaped particles. While relatively high temperatures and acidity can be used to obtain polyhedral particles [33]. Another effective way to obtain spheres, and the chosen pathway, is by using even higher temperatures and acidity. The high temperatures can affect the regularity of the micelles and reduce the interaction between the surfactant and the silica species consequently making them unable to template as a regular structure. In addition, the combination of high acidity and temperatures promotes the degradation of the surfactant which can lead to spherical particles by diverse mechanisms [36]. Table 1 displays the different supports and catalysts synthesized and their textural properties. The morphologies and impregnation methods of the materials are also detailed below. 
After the incorporation of the active phase by incipient wetness impregnation (Figure $2 \mathrm{~A}$ ), a shortening of the SBA-15 fibers is observed, attributed to the soft mechanical action that is introduced when mixing, in the homogenization process of this method. On the other hand, in the case of the fibers submitted to the incorporation treatment by ball milling, even shorter fibers and a greater distribution of particle size can be seen (Figure 2 B). As expected, the grinding has a more aggressive effect, resulting in more fractures. In the catalysts obtained from the incorporation of $\mathrm{Cu}$ and $\mathrm{Ce}$ in the rod-shaped SBA-15, no changes in morphology were observed, showing rods together with irregular and agglomerated formations (Figures $2 \mathrm{C}$ and D).

EDS studies revealed a homogeneous distribution of $\mathrm{Cu}$ and $\mathrm{Ce}$ for the 15-F/WI catalyst (Figure 3). Different regions were analyzed, obtaining compositions very close to the nominal $\mathrm{Si} / \mathrm{Ce} / \mathrm{Cu}=0.88 / 0.075 / 0.042$ (molar fraction, considering $\mathrm{Si}, \mathrm{Ce}$ and $\mathrm{Cu}$, excluding oxygen). Regarding the 15-F/BM catalyst, the analysis of the different regions suggested a certain degree of heterogeneity $(0.88 / 0.035 / 0.088 ; 0.88 / 0.053 / 0.060))$, also, some agglomerates were found. EDS analyses revealed a homogeneous distribution of $\mathrm{Cu}$ and $\mathrm{Ce}$ in $15-\mathrm{R} / \mathrm{WI}(0.87 / 0.08 / 0.05)$. In the catalyst $15-\mathrm{R} / \mathrm{BM}$ micrographs, irregular fragments of different compositions could be found: some composed mostly of Si $(0.96 / 0.020 / 0.015)$ and others with a higher concentration of $\mathrm{Cu}$ and $\mathrm{Ce}(0.67 / 0.222 / 0.105)$ (Supplementary materials, Figure S1).

SEM micrographs of the spherical SBA-16 based catalysts are shown in Figure 4. From the images, it can be noticed that in both cases the spheres were well preserved, even after being submitted to the grinding process. The catalyst 16-S/WI exhibits some "circles or halos" on the surface of the spheres (Figure 4 A). The EDS analyzes in a wide region showed elemental 
concentrations near to the nominal values $(0.835 / 0.110 / 0.055$, Figures $4 \mathrm{~B}$ and $\mathrm{C})$. The inspection of smaller regions of the particles revealed that the brightest areas could correspond mainly to $\mathrm{CeO}_{2}$ deposits which were caused by the accumulation of the solution, while the copper species appear to be homogeneously distributed. On the other hand, the 16S/BM catalyst revealed that the ball milling technique led to the formation of agglomerates enriched mainly in ceria (Figures 4 D, E and F). Some molar ratio values found for the agglomerates in different areas were $(0.681 / 0.244 / 0.075)$ and $(0.679 / 0.212 / 0.109)$. Nevertheless, the influence of the material roughness cannot be discarded in the EDS images obtained for each element.

Finally, in the 16-I/WI catalyst, the morphology conservation was observed without apparent agglomerate formation. In all the samples analyzed, the elements copper and cerium showed a homogeneous distribution. For example, the molar ratios were close to the nominal value at different points measured; 0.886/0.067/0.047 and 0.894/0.064/0.042 (Figure S1).

The EDS results suggest that the use of a volume of solvent equal to the pore volume in the incipient wetness impregnation method improves the distribution between the metal oxide phases. In this vein, it is known that this method is one of the simplest and most widely used for mesoporous materials, and is especially recommended when the adsorption of the precursor salts is relatively weak [55]. On the other hand, the incorporation of the active phase by ball milling shortens the fibers $(15-\mathrm{F} / \mathrm{BM})$ and produces some agglomerates and irregular fragments with a distribution of copper and cerium species further from the nominal values.

Figure 5 shows TEM images of the synthesized catalysts. The presence of the typical channels of the SBA-15 hexagonal structure in the different morphologies (Figures $5 \mathrm{~A}, \mathrm{~B}$ 
and C), as well as the characteristic cubic $\operatorname{Im} 3 m$ structure of the SBA-16 along the [100] direction (Figure $5 \mathrm{D}$ and Figure S2 D Supplementary Materials) can be noted. The micrographs revealed the incorporation of the active phase within the parallel channels of 15-F/WI and 15-F/BM catalysts (Figures $5 \mathrm{~A}$ and $\mathrm{B}$ ). Likewise, the preservation of the mesostructure and the presence of active phase nanoparticles inside the mesopores of catalyst 15-R/BM is verified in Figure 5 C. In the catalyst based on spherical SBA-16 (16-S/BM), oxides nanoparticles and conserved porous structure could be observed (Figure 5 D).

The oxides particle size distributions were estimated from TEM images are also shown in Figure 5 (graphics inserted) and Figure S2 (Supplementary Materials). During the impregnation stage of copper and cerium (wet impregnation or ball milling), inside the mesostructure a synergetic interaction between $\mathrm{CuO}$ and $\mathrm{CeO}_{2}$ oxides nanoparticles takes place. In this vein, the data show that the average size of the active phase is smaller than 10 $\mathrm{nm}$ in all catalysts.

In both SBA-15 materials prepared by incipient wetness impregnation, most of the particles observed presented an elongated-shape in the channels direction. As the size particle distribution and standard deviations suggest (Figures 5 A and S2 A), the length of these particles was quite variable compared with the rest of the samples, with average particle sizes equal to 7.4 and $8.0 \mathrm{~nm}$, for $15-\mathrm{F} / \mathrm{WI}$ and $15-\mathrm{R} / \mathrm{WI}$, respectively. In contrast, smaller and more spheroidal particles were observed when the active phase was incorporated by ball milling (Figures $5 \mathrm{~B}$ and C), also less dispersion in particle distribution was noticed (5.8 and $3.9 \mathrm{~nm}$ for $15-\mathrm{F} / \mathrm{BM}$ and $15-\mathrm{R} / \mathrm{BM}$, respectively).

On the other hand, the $\mathrm{CuO}-\mathrm{CeO}_{2}$ nanoparticles observed by TEM in SBA-16 based catalysts presented a small aspect ratio and homogenous size, regardless of the impregnation method 
used, average particle sizes between 5.3 and $6.4 \mathrm{~nm}$ (Figures $5 \mathrm{D}, \mathrm{S} 2 \mathrm{~B}$ and S2 C). This homogeneity could be attributed to the mesostructure, since the majority of the analyzed particles appear to be confined in the mesoporous spherical cavities, probably limiting particle size growth.

The solids were characterized by $\mathrm{N}_{2}$ adsorption-desorption in order to analyze their structure and textural properties. The measurements revealed type IVa isotherms for all synthesized supports [56]. In particular, the 15-F silica showed an H1 hysteresis cycle characteristic of the monodispersed cylindrical pores (Figure 6 A). As described in the literature, the SBA15 has a hexagonal pore arrangement with a non-intersection network of cylinders (2D hexagonal pore system). The BET area of the as-synthesized fibers was $650 \mathrm{~m}^{2} \mathrm{~g}^{-1}$ and their mesopore diameter calculated by the BJH-KJS method was $8.2 \mathrm{~nm}$ (Table 1). Furthermore, the DFT model was also used to analyze the pore size distribution (PSD) of the samples, revealing an underestimation of the pore size by the BJH-KJS method. The narrow PSD profile (15-F, Figure S3) evidences the presence of uniform cylindrical mesopores with a diameter of $9.2 \mathrm{~nm}$ by DFT model.

On the other hand, the rod-shaped SBA-15 exhibited a partially deformed hysteresis cycle. Concerning the $15-\mathrm{R}$ isotherm, the capillary condensation step is smaller, not as steep as the one of $15-\mathrm{F}$ and the hysteresis is also a mixture of $\mathrm{H} 1$ and $\mathrm{H} 3$ types, which indicates a greater dispersion in the pore size (Figure 6 B). For this sample, a broader PSD profile with the maximum of pore size centered at $7.8 \mathrm{~nm}$ can be observed in Figure S4. In addition, the hysteresis loop does not close in the area where the plateau is expected to be found, but at a higher $\mathrm{P} / \mathrm{P}^{\circ}$. These observations are in agreement with the presence of aggregates or presumably non-mesoporous silica particles observed in SEM micrographs. Nevertheless, 
this material showed specific area values typical of SBA-15 materials $570 \mathrm{~m}^{2} \mathrm{~g}^{-1}$ (Table 1). Likewise, the pore volume and diameter values are within the interval reported for this type of mesoporous silicas [49,57,58].

The pore size distribution profiles of catalysts based on SBA-15 resulted broader than their supports (Figures S3 and S4). The incorporation of $\mathrm{Cu}$ and Ce provokes the pore plugging that can be seen in the desorption branches of Figures 6 A and B.

Regarding sphere and irregular shaped SBA-16 solids, they presented a gradual pore filling on adsorption branch and a delayed pore emptying process with loop closures at $\mathrm{P} / \mathrm{P}^{\circ}$ around 0.42 corresponding to $\mathrm{H} 2$ hysteresis cycles (Figure $6 \mathrm{C}$ ). This is consistent with the presence of "ink-bottle" type mesopores characteristic of cubic caged 3D pore structure of SBA-16 mesoporous silica. The obtained supports presented specific surface areas between 680 and $650 \mathrm{~m}^{2} \mathrm{~g}^{-1}$ with the pore size distribution profiles centered at 6.7 and $6.9 \mathrm{~nm}$, for $16-\mathrm{S}$ and 16-I, respectively (Table 1 and Figures S5 and S6). These values are closed to those reported in the literature for these materials $[40,59,60]$. The PSD profiles showed a wide range of pore sizes between 6-16 $\mathrm{nm}$ in 16-I/WI (Figure S6) with maximum values at 7.1 and $7.8 \mathrm{~nm}$, while in Figure S5 appear a broader peak centered at $5.3 \mathrm{~nm}(16-\mathrm{S} / \mathrm{BM})$.

It should be mentioned that for the pore size assessment of the as-synthesized SBA-16 and SBA-16 based catalysts, the adsorption branch was chosen since the percolation phenomenon caused by the cage-like structure leads to inaccurate estimations. In addition, the closing points of the desorption branches of hysteresis loops suggest that the pore windows are around $4 \mathrm{~nm}$ or smaller $[61,62]$. The DFT model used to estimate the mesopore diameters may underestimate slightly the pore size for the spherical cage-like geometry [63]. 
In all catalysts, the incorporation of the $\mathrm{CuO}-\mathrm{CeO}_{2}$ active phases decreased the surface area and pore volume, due to the presence of oxide nanoparticles inside the pore. In Table 1 it can be observed that the specific areas of the impregnated materials decreased around 30-40 $\%$ and about $50 \%$, for SBA-15 and SBA-16 based materials, respectively.

The 15-F/WI preserved relatively high pore volume $\left(0.52 \mathrm{~cm}^{3} \mathrm{~g}^{-1}\right)$ compared with the other catalysts, particularly for catalysts based on SBA-16 where their pore volume values decreased more than $50 \%$.

Figure 7 displays the SAXS patterns of the catalysts obtained by ball milling. The patterns corresponding to $15-\mathrm{F} / \mathrm{BM}$ and 15-R/BM (Figures $7 \mathrm{~A}$ and $\mathrm{B}$ ) exhibit a main peak and two less intense ones corresponding to the reflections planes (100), (110) and (200) respectively, which confirm the characteristic porous arrangement of the unidirectional structure of SBA15. The position of the peaks and the corresponding d-spacings are listed in Table 2 . These planes are characteristic for the $P 6 \mathrm{~mm}$ symmetry group, in agreement with values previously reported for this material $[53,64]$. The unit cell dimensions $\left(a_{0}\right)$ calculated from $\mathrm{d}_{100}$ have values of 11.3 and $10.2 \mathrm{~nm}$ for the catalysts based on SBA-15 fibers and rods, respectively.

The measurement carried out on catalyst $16-\mathrm{S} / \mathrm{BM}$ allowed to identify the peaks corresponding to the diffraction planes (110), (200) and (211) (Figure 6 C). The a cell unit parameter calculated from (110) and (200) planes was $14.1 \mathrm{~nm}$ (see Table 2), confirming the three-dimensional cubic cage structure (Im3m space group) of SBA-16 [65].

From the analysis of the results obtained for mesoporous catalysts, it is possible to confirm that the structural characteristics are preserved, even after incorporating the $\mathrm{CuO}-\mathrm{CeO}_{2}$ active phase. Although the incorporation of the oxides caused a decrease in the values of surface area and pore volume, no significant damage in the mesoporous structure was observed. 
Furthermore, it was possible to obtain a good distribution of the oxide nanoparticles in the mesoporous cavities without the formation of large agglomerates.

The wide-angle X-ray diffraction technique was used to identify the crystalline phases existing in the catalysts. Figure 8 presents the patterns and Table 3 displays the crystallite sizes estimated by Scherrer's equation of the catalysts based on SBA-15 and SBA-16 mesoporous silicas. In the diffractograms, the main peaks that appear at $2 \theta$ equal to 28.58 ; $33.11 ; 47.52$ and 56.38 degrees correspond to the fluorite phase of the ceria. In addition, the halo of amorphous silica located around 25 degrees can be identified. On the other hand, no signs of copper species were detected, indicating that the copper is well dispersed or forming a solid solution. Despite the fact that the diffraction patterns show lattice parameters similar to the bulk $\mathrm{CeO}_{2}$ reference value $(0.54131 \mathrm{~nm})$, our previous Raman studies in $\mathrm{CuO}$ $\mathrm{CeO}_{2} / \mathrm{SiO}_{2}$ materials suggested the incorporation of $\mathrm{Cu}$ species into the ceria lattice [45].

Table 3 shows the average particle size of $\mathrm{CuO}-\mathrm{CeO}_{2}$ nanoparticles obtained from XRD and TEM images (Figures 5 and S2). The crystallite sizes of $\mathrm{CeO}_{2}$ in all catalysts, estimated from Scherrer's equation, are between 4.9 and $5.9 \mathrm{~nm}$, which are in the same magnitude order that pore size obtained by the DFT model (Table 1). These results are in good agreement with TEM observations. In addition, it can be concluded that the presence of solvent is not essential to disperse the host species in the support. XRD and TEM analysis showed that, as an alternative to conventional incipient wetness impregnation, solid-state impregnation can disperse species of copper and ceria on all substrates.

XPS was used to analyze the chemical state and relative surface abundance of the elements present in the catalysts. It is worth noting that the experiment performed corresponds to the fresh catalysts before the chemical reaction. The data represent the initial state of the solid 
taking into account that the chemical species on the surface can change in presence of the reagents (the reaction mixture has reducing properties, with $40 \%$ of $\mathrm{H}_{2}$ ).

The Ce $3 \mathrm{~d}$ complex spectra presented two sets of spin-orbital multiplets, corresponding to the $3 d_{3 / 2}$ and $3 d_{5 / 2}$ contributions, which are labeled as $u$ and $v$, respectively. The lower binding energy (B.E.) peaks at $882.7,888.4$ and $898.3 \mathrm{eV}$, correspond to v, v', v', peaks are characteristic of $3 \mathrm{~d}_{5 / 2}$ level of $\mathrm{Ce}^{4+}$ species $\left(\mathrm{CeO}_{2}\right)$. While other three $\mathrm{u}$, u' and $\mathrm{u}^{\prime \prime}$ ' located at $901.2,907.3$ and $916.8 \mathrm{eV}$, respectively were assigned to $\mathrm{Ce} 3 \mathrm{~d}_{3 / 2}$. In addition, signals attributed to $\mathrm{Ce}^{3+}$ species are designated as $v^{\circ}$ and $v^{\prime}\left(3 \mathrm{~d}_{5 / 2}\right)$, $\mathrm{u}^{\circ}$ and $\mathrm{u}^{\prime}\left(3 \mathrm{~d}_{3 / 2}\right)$, respectively (Figure S7) [66]. The signals found in our studied catalysts (Ce $3 \mathrm{~d}_{5 / 2}$ and $\mathrm{Ce} 3 \mathrm{~d}_{3 / 2}$ regions) were slightly shifted towards higher binding energies $(\sim 0.5 \mathrm{eV})$, probably due to the interaction between $\mathrm{Ce}$ and $\mathrm{Cu}$ species in the nanometric particles or the formation of solid solution $\mathrm{CuCeO}_{\mathrm{x}}$.

The overlapping of the numerous components described above on the $\mathrm{Ce} 3 \mathrm{~d}$ region complicated the analysis of the different species present on the surface. Nevertheless, the ratio between $\mathrm{Ce} 3 \mathrm{~d}_{3 / 2} \mathrm{u}^{\prime \prime},(\sim 917.0 \mathrm{eV})$ peak and the total Ce $3 \mathrm{~d}$ intensities could be linked to the concentration of oxidized $\mathrm{Ce}^{4+}$ species, where $\mathrm{I}_{\mathrm{u}^{\prime}}{ }^{\prime \prime} / \mathrm{I}_{\mathrm{Ce}}$ tot $=0.14$ implies $100 \% \mathrm{Ce}^{4+}$ [67]. From Table 3, it can be observed that all catalysts showed mainly $\mathrm{CeO}_{2}$ with the presence of $\mathrm{Ce}^{3+}$ species in some samples $(15-\mathrm{F} / \mathrm{WI}, 15-\mathrm{R} / \mathrm{BM}$ and $16-\mathrm{I} / \mathrm{WI})$, related to oxygen vacancies in the ceria lattice surface.

On the other hand, the complete $\mathrm{Cu} 2 \mathrm{p}_{3 / 2-1 / 2}$ region was analyzed and Figure 9 shows the catalysts spectra of $\mathrm{Cu} 2 \mathrm{p}_{3 / 2}$ level. It is possible to observe the broad main peak between 928 and $938 \mathrm{eV}$, which denotes the presence of different copper species. The component that appears at BEs above $933.5 \mathrm{eV}$ corresponds to $\mathrm{Cu}^{2+}$ (Table 3). These values are higher than 
pure copper (II) oxide $(\sim$ B.E. $=933.5 \mathrm{eV}[68])$, which suggests certain influence of $\mathrm{SiO}_{2}$ support. The characteristic satellite peak of $\mathrm{Cu}^{2+}$ species is located at a higher binding energy value (Figure 9). The asymmetry noted in the main peak at lower B.E. suggests another component in a B.E. range of $932.8-933.1 \mathrm{eV}$, which is attributed to $\mathrm{Cu}^{+}$or $\mathrm{Cu}^{0}$ species on the surface. The absence of metallic $\mathrm{Cu}$ signal was validated by Auger spectra measured for all catalysts. Moreover, all the catalysts showed higher $\mathrm{Cu}^{+}$values than the monometallic sample (Table 3), which suggests that the presence of Ce promotes the formation of reduced copper species $\left(\mathrm{Cu}^{+}\right)$on the surface of the catalyst [69]. It is noteworthy that $\mathrm{Cu}^{+}$is regarded as an adsorption site for the chemisorption and the activation of $\mathrm{CO}$ molecules during the $\mathrm{CO}$ oxidation reaction.

The $\mathrm{Cu} / \mathrm{Ce}$ surface ratios of catalysts are listed in Table 3 . The results show that the $\mathrm{Cu} / \mathrm{Ce}$ values of samples prepared by BM method are higher than the materials obtained by WI. In this vein, in our previous work [50] we identified the molar $\mathrm{Cu} / \mathrm{Ce}$ ratio in $\mathrm{CuCe} / \mathrm{SBA}-15$ catalysts as a key variable to obtain good catalytic behavior, where $\mathrm{Cu} / \mathrm{Ce}=0.55$ was an optimal ratio among the studied materials. Furthermore, other authors $[31,70]$ have prepared bulk and supported $\mathrm{CuCe}$ catalysts with similar $\mathrm{Cu} / \mathrm{Ce}$ ratios and obtained good catalytic performance.

In order to assess the catalytic activity, all the catalysts synthesized were evaluated in CO preferential oxidation. Figure 10 depicts the $\mathrm{CO}$ conversion and oxygen selectivity curves. It can be observed that the SBA-15 based catalysts, both fibers and rods, and prepared by wet impregnation (WI) had the highest conversion values. In particular, the 15-F/WI catalyst achieved more than $98 \% \mathrm{CO}$ conversion at $175{ }^{\circ} \mathrm{C}$ and presented a window above $90 \%$ between 155 and $190{ }^{\circ} \mathrm{C}$. In the case of rod SBA-15 (15-R/WI), it showed a maximum 
conversion of $84 \%$ at $175{ }^{\circ} \mathrm{C}$. On the other hand, the catalysts prepared by BM, both fibers and rods, conversions lower than $75 \%$ were reached. The selectivity of $\mathrm{O}_{2}$ to $\mathrm{CO}_{2}$ of $15-$ F/WI was $58 \%$ at $175{ }^{\circ} \mathrm{C}$. The $\mathrm{O}_{2}$ selectivity of this catalyst was the highest when the temperature was above $170{ }^{\circ} \mathrm{C}$. For the rest of the catalysts, the selectivity profiles were similar between them.

When analyzing the surface of catalysts that were the most active, prepared by WI, 15-F/WI and 15-R/WI, the $\mathrm{Cu}^{+}$signal was located at B.E. $=932.9 \mathrm{eV}$ and the $\mathrm{Cu}^{2+}$ values were 933.8 $\mathrm{eV}$ and $934.4 \mathrm{eV}$, respectively (Table 3). Besides, the $\mathrm{Cu} / \mathrm{Ce}$ ratio on the surface resulted close to the nominal one.

The group of SBA-15 prepared by BM, 15-R/BM and 15-F/BM, which showed lower CO conversion (74 \% and $67 \%$, respectively), was characterized by higher B.E. values corresponding to $\mathrm{Cu}^{2+}($ B.E. $=935.3 \mathrm{eV})$. This behavior could be related to a greater interaction with the support. Also, greater surface $\mathrm{Cu} / \mathrm{Ce}$ ratios than the nominal one were detected (0.77 and 0.82).

In the SBA-16 structure, it was observed that catalysts with spherical morphology have similar catalytic behavior, where 16-S/WI reached its maximum conversion at higher temperatures than 16-S/BM (Figure 10). The catalyst with irregular morphology obtained by WI showed the best performance, with a CO conversion of $80 \%$ at $175{ }^{\circ} \mathrm{C}$. At lower temperatures, 16-I/WI exhibited better selectivity. All SBA-16 based catalysts had similar selectivity values between 175 and $200{ }^{\circ} \mathrm{C}$. In particular, the most active catalyst presented a high $\mathrm{Cu}^{+}$concentration on the surface and a $\mathrm{Cu} / \mathrm{Ce}$ ratio close to the nominal one. In contrast, 16-S/WI showed lower $\mathrm{Cu}^{+}$concentration and $\mathrm{Cu} / \mathrm{Ce}$ ratio equal to 0.30 . This is in agreement 
with SEM-EDS results, where a halo of $\mathrm{CeO}_{2}$ was observed on the sphere surface, which impairs the conversion due to a low copper concentration.

According to the catalytic behaviors and the study of materials by different characterizations, some observations can be pointed out, since there are many factors that affected the catalytic activity.

As a general trend the incipient wetness impregnation method produced better catalysts, which can be attributed to higher active phase distribution and the surface $\mathrm{Cu} / \mathrm{Ce}$ molar ratio closer to the nominal value. In most cases, the SBA-15 based catalysts showed better CO conversions and selectivities than those of SBA-16 based catalysts. In this sense, the characteristic cylindrical pores of SBA-15 would favor the interaction between gaseous reagents and the active phase. Particularly, the catalytic fibers showed the highest surface area, pore volume and diameter. On the other hand, the mesostructure of SBA-16 with inkbottle pores could hinder the incorporation of the nanoparticles and the transport of gases.

Previous studies have established that a good interaction between $\mathrm{Cu}$ and $\mathrm{Ce}$ species is imperative to promote the selective catalytic oxidation of $\mathrm{CO}$ and the partially reduced copper is its main adsorption site [69]. In this line, the XPS data suggest that the best catalysts were those which presented a certain amount of reduced copper species in combination with an adequate $\mathrm{Cu} / \mathrm{Ce}$ molar ratio on its surface. The EDS analyses revealed that the WI impregnation method generates a more homogeneous distribution of the active phase over the different supports. In contrast, these analyses showed a heterogeneous distribution and some agglomerates of the oxides incorporated by BM method.

Regarding the same incorporation method of the active phase, the SBA-15 based catalysts were more active than those prepared from SBA-16. In this sense, SEM micrographs and 
EDS analyses revealed that the incorporation of the active phase into the mesopores was not complete for SBA-16 materials (more visible in the spheres). This can be explained by the lower pore volume of as-synthesized SBA-16 and, as mentioned above, its porous structure. It should be taken into account that the active phase concentration and impregnation methods remained exactly the same for all supports, and further optimization of the metallic precursors quantities for 16-S and 16-I might be necessary.

TEM images revealed that the shapes and sizes of $\mathrm{CuO}-\mathrm{CeO}_{2}$ nanoparticles were conditioned by the mesostructures and the impregnation method. In this vein, the bidimensional channels characteristic of the SBA-15 silica allowed the formation of elongated-shape particles of 7.4 - $8.0 \mathrm{~nm}$ on 15-F/WI and 15-R/WI. Meanwhile, the materials prepared by BM showed smaller and less dispersed sized particles (5.7 and $3.9 \mathrm{~nm}$, for 15-F/BM and 15-R/BM).

On the other hand, the particles found within the SBA-16 porous array appear to be limited by the size of the main spherical pores. In this vein, the impregnation method was not a determinant factor, since the particles were relatively small and presented roughly the same size for all materials. This could partly explain their similar catalytic behavior. In addition, the active phase particle sizes, determined by TEM, were bigger than the pore windows sizes of the as-synthesized SBA-16 materials (below $4 \mathrm{~nm}$, estimated by $\mathrm{N}_{2}$ physisorption). This fact in combination with their relative lower pore volume could lead to the complete obstruction of some mesopores, preventing access of the reagents to a fraction of the active sites. However, it is possible that significantly bigger $\mathrm{CuO}-\mathrm{CeO}_{2}$ particles found outside of the spherical SBA-16 (SEM-EDS) contributed to damp the catalytic activity of these materials $[71,72]$. 


\section{Conclusions}

In the present work, ordered mesoporous silicas were synthesized using different pathways in which some synthesis variables were changed in order to modify the morphology of materials. In this vein, SEM images revealed SBA-15 with fiber and rod morphologies and SBA-16 with spherical and irregular morphologies. Fibers (15-F), whose length was around 30-40 $\mu \mathrm{m}$ and thickness $5 \mu \mathrm{m}$, and rods (15-R) of $1 \times 0.2 \mu \mathrm{m}$ were obtained for SBA-15. The spherical SBA-16 showed particles of 2-5 $\mu \mathrm{m}$, whereas when butanol was used as cosurfactant irregular fragments $(2-30 \mu \mathrm{m})$ were obtained (16-I).

The mesoporous structures of supports and catalysts were verified by Transmission Electron Microscopy, $\mathrm{N}_{2}$ sorption and SAXS analyses. TEM images revealed that both impregnation methods produced $\mathrm{CuO}-\mathrm{CeO}_{2}$ nanoparticles with sizes smaller than $10 \mathrm{~nm}$ inside the mesopores. Nevertheless, EDS-SEM analyses showed a more homogenous distribution of $\mathrm{Cu}$ and $\mathrm{Ce}$ in the materials prepared by the incipient wetness impregnation method (WI).

The catalytic performance was benefited when the catalysts were prepared by incipient wet impregnation. However, several factors in a complex system $\mathrm{CuO}-\mathrm{CeO}_{2} / \mathrm{SBA}$ contributed to promoting CO oxidation. While the homogeneous cylindrical pore of the SBA-15 (fibers and rods) improves the intimate contact between active centers and the reactants, the "ink-bottle" type mesopores of SBA-16 would be obstructed by the active phase. In addition, XPS analysis showed for the best catalysts the combination of reduced copper species with $\mathrm{Cu} / \mathrm{Ce}$ molar ratio close to the nominal one.

\section{Acknowledgments}


The authors wish to acknowledge the financial support received from UNL, ANPCyT, CONICET and to Ministry of Science, Technology and Innovation of Santa Fe (MinCTIPASACTei) for the Grant (AC-2015-0002) for the purchase of TEM -JEOL 2100-plus. Thanks are given to María Fernanda Mori (INCAPE, Santa Fe, Argentina) for the XPS measurements, to Mélanie Emo (L2CM, University of Lorraine, France) for SAXS analyses, to Loïc Vidal (IS2M, Mulhouse, France) for TEM observations and to Ludovic Josien (IS2M, Mulhouse, France) for SEM-EDS analyses.

\section{References}

[1] E.D. Park, D. Lee, C.H. Lee, Recent progress in selective $\mathrm{CO}$ removal in a $\mathrm{H} 2$-rich stream, Catal. Today. 139 (2009) 280-290. doi:10.1016/j.cattod.2008.06.027.

[2] L.M.T. Martínez, O.H. Laguna, M.A. Centeno, Synthesis and characterization of Rh/MnO2CeO2/A12O3 catalysts for CO-PrOx reaction, Mol. Catal. 440 (2017) 9-18.

[3] L. Soler, A. Casanovas, A. Urrich, I. Angurell, J. Llorca, CO oxidation and COPrOx over preformed Au nanoparticles supported over nanoshaped CeO2, Appl. Catal. B Environ. 197 (2016) 47-55. doi:10.1016/j.apcatb.2016.02.025.

[4] L.E. Gómez, B.M. Sollier, A.M. Lacoste, E.E. Miró, A. V Boix, Hydrogen purification for fuel cells through $\mathrm{CO}$ preferential oxidation using $\mathrm{PtCu} / \mathrm{Al} 2 \mathrm{O} 3$ structured catalysts, J. Environ. Chem. Eng. 7 (2019) 103376. doi:10.1016/j.jece.2019.103376.

[5] J. Lu, J. Wang, Q. Zou, Y. Zhao, J. Fang, S. He, D. He, Y. Luo, Catalytic performance of transition metals $(\mathrm{Co}, \mathrm{Ni}, \mathrm{Zn}, \mathrm{Mo})$ doped $\mathrm{CuO}-\mathrm{Ce} 0.8 \mathrm{Zr} 0.2 \mathrm{O} 2$ based catalysts for $\mathrm{CO}$ preferential oxidation in H2 -rich streams, J. Alloys Compd. 784 (2019) 1248-1260. doi:10.1016/j.jallcom.2019.01.107.

[6] M. Cargnello, V.V.T. Doan-Nguyen, T.R. Gordon, R.E. Diaz, E.A. Stach, R.J. Gorte, P. Fornasiero, C.B. Murray, Control of Metal Nanocrystal Size Role for Ceria Catalysts, Science (80-. ). 341 (2013) 771-773. doi:10.1126/science.1240148.

[7] S. Bernal, J.J. Calvino, M.A. Cauqui, J.M. Gatica, C. Larese, J.A. Pérez Omil, J.M. Pintado, Some recent results on metal/support interaction effects in NM/CeO2 (NM: noble metal) catalysts, Catal. Today. 50 (1999) 175-206.

[8] N. Qiu, J. Zhang, Z. Wu, Peculiar surface - interface properties of nanocrystalline ceria - 
cobalt oxides with enhanced oxygen storage capacity, Phys. Chem. Chem. Phys. 16 (2014) 22659-22664. doi:10.1039/C4CP03390F.

[9] X. Guo, C. Mao, J. Zhang, J. Huang, W. Wang, Y. Deng, Y.-Y. Wang, Y. Cao, W.-X. Huang, S.-H. Yu, Cobalt-Doping-Induced Synthesis of Ceria Nanodisks and Their Signifi cantly Enhanced Catalytic Activity, Small. 8 (2012) 1-6. doi:10.1002/smll.201102179.

[10] L.F. Liotta, H. Wu, G. Pantaleo, A.M. Venezia, Co3O4 nanocrystals and Co3O4-MOx binary oxides for $\mathrm{CO}, \mathrm{CH} 4$ and VOC oxidation at low temperatures: a review, Catal. Sci. Technol. 3 (2013) 3085-3102. doi:10.1039/c3cy00193h.

[11] L.-Y. Lee, A. Jha, W.-J. Jang, J.-O. Shim, K.-W. Jeon, H.-S. Na, H.-M. Kim, D.-W. Lee, S.Y. Yoo, B.-H. Jeon, J.W. Bae, H.-S. Roh, Optimization of Cobalt Loading in Co-CeO2 Catalyst for the High Temperature Water-Gas Shift Reaction, Top. Catal. 60 (2017) 721726. doi:10.1007/s11244-017-0776-2.

[12] S.A.C. Carabineiro, X. Chen, M. Konsolakis, A.C. Psarras, P.B. Tavares, J.J.M. Órfão, M.F.R. Pereira, J.L. Figueiredo, Catalytic oxidation of toluene on Ce-Co and La-Co mixed oxides synthesized by exotemplating and evaporation methods, Catal. Today. 244 (2014) 161-171. doi:10.1016/j.cattod.2014.06.018.

[13] Z. Wang, J. Lan, M. Haneda, Z. Liu, Selective catalytic reduction of NOx with NH3 over a novel Co-Ce-Ti catalyst, Catal. Today. (2020) in press. doi:10.1016/j.cattod.2020.05.040.

[14] L.E. Gómez, J.F. Múnera, B.M. Sollier, E.E. Miró, A. V. Boix, Raman in situ characterization of the species present in $\mathrm{Co} / \mathrm{CeO} 2$ and $\mathrm{Co} / \mathrm{ZrO} 2$ catalysts during the $\mathrm{COPrOx}$ reaction, Int. J. Hydrogen Energy. 41 (2016) 4993-5002. doi:10.1016/j.ijhydene.2016.01.099.

[15] Z. Gholami, G. Luo, Kinetics, Catalysis , and Reaction Engineering Low-temperature selective catalytic reduction of $\mathrm{NO}$ by $\mathrm{CO}$ in the presence of $\mathrm{O} 2$ over $\mathrm{Cu}$ :Ce catalysts supported by multi-walled carbon nanotubes, Ind. Eng. Chem. Res. 57 (2018) 8871-8883. doi:10.1021/acs.iecr.8b01343.

[16] C. Chen, Y. Zhan, J. Zhou, D. Li, Y. Zhang, X. Lin, L. Jiang, Q. Zheng, Cu/CeO2 Catalyst for Water-Gas Shift Reaction: Effect of CeO2 Pretreatment, ChemPhysChem. 19 (2018) 1448-1455. doi:10.1002/cphc.201800122.

[17] T. Tsoncheva, G. Issa, T. Blasco, M. Dimitrov, M. Popova, S. Hernández, D. Kovacheva, G. Atanasova, J.M. López Nieto, Catalytic VOCs elimination over copper and cerium oxide modified mesoporous SBA-15 silica, Appl. Catal. A, Gen. 453 (2013) 1-12. doi:10.1016/j.apcata.2012.12.007.

[18] W. Shen, D. Mao, Z. Luo, J. Yu, CO oxidation on mesoporous SBA-15 supported CuO- 
$\mathrm{CeO} 2$ catalyst prepared by a surfactant-assisted impregnation method, RSC Adv. 7 (2017) 27689-27698. doi:10.1039/c7ra02966g.

[19] J. Papavasiliou, M. Rawski, J. Vakros, G. Avgouropoulos, A Novel Post-Synthesis Modification of CuO-CeO2Catalysts: Effect on Their Activity for Selective CO Oxidation, ChemCatChem. 10 (2018) 2096-2106. doi:10.1002/cctc.201701968.

[20] A. Martínez-Arias, D. Gamarra, A. Hungría, M. Fernández-García, G. Munuera, A. Hornés, P. Bera, J. Conesa, A. Cámara, Characterization of Active Sites/Entities and Redox/Catalytic Correlations in Copper-Ceria-Based Catalysts for Preferential Oxidation of CO in H2-Rich Streams, Catalysts. 3 (2013) 378-400. doi:10.3390/catal3020378.

[21] S. Yao, K. Mudiyanselage, W. Xu, A.C. Johnston-Peck, J.C. Hanson, T. Wu, D. Stacchiola, J.A. Rodriguez, H. Zhao, K.A. Beyer, K.W. Chapman, P.J. Chupas, A. Martínez-Arias, R. $\mathrm{Si}$, T.B. Bolin, W. Liu, S.D. Senanayake, Unraveling the Dynamic Nature of a $\mathrm{CuO} / \mathrm{CeO} 2$ Catalyst for CO Oxidation in Operando: A Combined Study of XANES (Fluorescence) and DRIFTS, Catalysis. 4 (2014) 1650-1661.

[22] M. Lykaki, E. Pachatouridou, S.A.C. Carabineiro, E. Iliopulou, C. Andriopoulou, N. Kallithrakas-Kontos, S. Boghosian, M. Konsolakis, Ceria nanoparticles shape effects on the structural defects and surface chemistry: implications in $\mathrm{CO}$ oxidation by $\mathrm{Cu} / \mathrm{CeO} 2$ oxides, "Applied Catal. B, Environ. 230 (2018) 18-28. doi:10.1016/j.apcatb.2018.02.035.

[23] B. Liu, W. Li, W. Song, J. Liu, Carbonate-mediated Mars-van Krevelen mechanism for CO oxidation on cobalt-doped ceria catalysts: facet-dependence and coordination-dependence, Phys. Chem. Chem. Phys. 20 (2018) 16045-16059. doi:10.1039/C8CP01694A.

[24] X. Guo, R. Zhou, A new insight into the morphology effect of ceria on $\mathrm{CuO} / \mathrm{CeO} 2$ catalysts for CO selective oxidation in hydrogen-rich gas, Catal. Sci. Technol. 6 (2016) 3862-3871. doi:10.1039/C5CY01816A.

[25] A. Jia, S. Jiang, J. Lu, M. Luo, Study of Catalytic Activity at the CuO - CeO2 Interface for CO Oxidation, J. Phys. Chem. C. (2010) 21605-21610.

[26] S. Li, N. Wang, Y. Yue, G. Wang, Z. Zu, Y. Zhang, Copper doped ceria porous nanostructures towards a highly efficient bifunctional catalyst for carbon monoxide and nitric oxide elimination, Chem. Sci. 6 (2015) 2495-2500. doi:10.1039/c5sc00129c.

[27] C. Chen, R. Wang, P. Shen, D. Zhao, N. Zhang, Inverse $\mathrm{CeO} / \mathrm{CuO}$ catalysts prepared from heterobimetallic metal-organic framework precursor for preferential $\mathrm{CO}$ oxidation in $\mathrm{H} 2-$ rich stream, Int. J. Hydrogen Energy. 40 (2015) 4830-4839. doi:10.1016/j.ijhydene.2015.02.066.

[28] G. Águila, F. Gracia, P. Araya, $\mathrm{CuO}$ and $\mathrm{CeO} 2$ catalysts supported on $\mathrm{Al} 2 \mathrm{O} 3, \mathrm{ZrO} 2$, and 
$\mathrm{SiO} 2$ in the oxidation of $\mathrm{CO}$ at low temperature, Appl. Catal. A Gen. 343 (2008) 16-24. doi:10.1016/j.apcata.2008.03.015.

[29] J. Luo, W. Chu, H. Xu, C. Jiang, T. Zhang, Low-temperature CO oxidation over CuO$\mathrm{CeO} 2 / \mathrm{SiO} 2$ catalysts: Effect of $\mathrm{CeO} 2$ content and carrier porosity, J. Nat. Gas Chem. 19 (2010) 355-361. doi:10.1016/S1003-9953(09)60088-8.

[30] Y. Chen, Y. Liu, D. Mao, J. Yu, Y. Zheng, X. Guo, Z. Ma, Facile cyclodextrin-assisted synthesis of highly active $\mathrm{CuO}-\mathrm{CeO} 2 / \mathrm{MCF}$ catalyst for $\mathrm{CO}$ oxidation, J. Taiwan Inst. Chem. Eng. In press (2020). doi:https://doi.org/10.1016/j.jtice.2020.07.015.

[31] C. Tang, J. Sun, X. Yao, Y. Cao, L. Liu, C. Ge, F. Gao, L. Dong, Efficient fabrication of active $\mathrm{CuO}-\mathrm{CeO} 2 / \mathrm{SBA}-15$ catalysts for preferential oxidation of $\mathrm{CO}$ by solid state impregnation, Appl. Catal. B Environ. 146 (2014) 201-212. doi:10.1016/j.apcatb.2013.05.060.

[32] J. Wu, X. Zhao, L. Xue, H. Su, S. Zeng, Barrier effect of SiO2 shell over hollow $\mathrm{CeO} 2 / \mathrm{CuO} @ \mathrm{SiO} 2$ catalysts for broadening temperature window of total $\mathrm{CO}$ conversion, J. Rare Earths. 38 (2019) 46-57. doi:10.1016/j.jre.2018.11.005.

[33] C. Yu, J. Fan, B. Tian, D. Zhao, Morphology Development of Mesoporous Materials: a Colloidal Phase Separation Mechanism, Chem. Mater. 16 (2004) 889-898. doi:10.1021/cm035011g.

[34] W.J.J. Stevens, K. Lebeau, M. Mertens, G. Van Tendeloo, P. Cool, E.F. Vansant, Investigation of the Morphology of the Mesoporous SBA-16 and SBA-15 Materials, J. Phys. Chem. B. 110 (2006) 9183-9187. doi:10.1021/jp0548725.

[35] W.J.J. Stevens, M. Mertens, S. Mullens, I. Thijs, G. Van Tendeloo, P. Cool, E.F. Vansant, Formation mechanism of SBA-16 spheres and control of their dimensions, Microporous Mesoporous Mater. 93 (2006) 119-124. doi:10.1016/j.micromeso.2006.02.015.

[36] M. Mesa, L. Sierra, J. Patarin, J.-L. Guth, Morphology and porosity characteristics control of SBA-16 mesoporous silica. Effect of the triblock surfactant Pluronic F127 degradation during the synthesis, Solid State Sci. 7 (2005) 990-997. doi:10.1016/j.solidstatesciences.2005.04.006.

[37] P. Linton, V. Alfredsson, Growth and Morphology of Mesoporous SBA-15 Particles, Chem. Mater. 20 (2008) 2878-2880.

[38] J. Xu, J. Zhang, H. Peng, X. Xu, W. Liu, Z. Wang, N. Zhang, X. Wang, Ag supported on meso-structured $\mathrm{SiO} 2$ with different morphologies for $\mathrm{CO}$ oxidation : On the inherent factors in fl uencing the activity of Ag catalysts, Microporous Mesoporous Mater. 242 (2017) 9098. doi:10.1016/j.micromeso.2017.01.016. 
[39] Z. Jin, H. Liang, Effects of Morphology and Structural Characteristics of Ordered SBA-15 Mesoporous Silica on Release of Ibuprofen Effects of Morphology and Structural Characteristics of Ordered SBA-15 Mesoporous Silica on Release of Ibuprofen, J. Dispers. Sci. Technol. 31 (2010) 37-41. doi:10.1080/01932690903218617.

[40] Z. Cao, P. Du, A. Duan, R. Guo, Z. Zhao, H. lei Zhang, P. Zheng, C. Xu, Z. Chen, Synthesis of Mesoporous Materials SBA-16 with Different Morphologies and Their Application in Dibenzothiophene Hydrodesulfurization, Chem. Eng. Sci. 155 (2016) 141-152. doi:10.1016/j.ces.2016.08.001.

[41] S. Govender, H.B. Friedrich, Monoliths: A review of the basics, preparation methods and their relevance to oxidation, Catalysts. 7 (2017) 62. doi:10.3390/catal7020062.

[42] P.S. Barbato, A. Di Benedetto, G. Landi, L. Lisi, $\mathrm{CuO} / \mathrm{CeO} 2$ based monoliths for $\mathrm{CO}$ preferential oxidation in H2-rich streams, Chem. Eng. J. 279 (2015) 983-993. doi:10.1016/j.cej.2015.05.079.

[43] H. Pérez, P. Navarro, M. Montes, Deposition of SBA-15 layers on Fecralloy monoliths by washcoating, Chem. Eng. J. 158 (2010) 325-332. doi:10.1016/j.cej.2010.01.032.

[44] M. Blažek, M. Žalud, P. Kočí, A. York, C.M. Schlepütz, M. Stampanoni, V. Novák, Washcoating of catalytic particulate filters studied by time-resolved X-ray tomography, Chem. Eng. J. 409 (2021) 128057. doi:10.1016/j.cej.2020.128057.

[45] I.S. Tiscornia, A.M. Lacoste, L.E. Gómez, A. V Boix, $\mathrm{CuO-CeO2/SiO2} \mathrm{coating} \mathrm{on} \mathrm{ceramic}$ monolith: Effect of the nature of the catalyst support on $\mathrm{CO}$ preferential oxidation in a $\mathrm{H} 2-$ rich stream, Int. J. Hydrogen Energy. 45 (2020) 6636-6650. doi:10.1016/j.ijhydene.2019.12.126.

[46] A.K. Medina-Mendoza, C. Angeles-Chavez, M.A. Cortes-Jacome, J.A. Toledo-Jntonio, Structural analysis of a Pt e Pd core-shell/Al-SBA-15 catalyst synthesized by the solid-state impregnation route, Mater. Chem. Phys. 228 (2019) 303-309. doi:10.1016/j.matchemphys.2019.02.069.

[47] P. Gaudin, S. Dorge, H. Nouali, M. Vierling, E. Fiani, M. Molière, J.F. Brilhac, J. Patarin, $\mathrm{CuO} / \mathrm{SBA}-15$ materials synthesized by solid state grinding: Influence of $\mathrm{CuO}$ dispersion and multicycle operation on DeSOX performances, Appl. Catal. B Environ. 181 (2016) 379388. doi:10.1016/j.apcatb.2015.08.011.

[48] Q. Zhang, T. Zhang, Y. Shi, B. Zhao, M. Wang, Q. Liu, J. Wang, K. Long, Y. Duan, P. Ning, A sintering and carbon-resistant Ni-SBA-15 catalyst prepared by solid-state grinding method for dry reforming of methane, Biochem. Pharmacol. 17 (2017) 10-19. doi:10.1016/j.jcou.2016.11.002. 
[49] V. Meynen, P. Cool, E.F. Vansant, Verified syntheses of mesoporous materials, Microporous Mesoporous Mater. 125 (2009) 170-223.

doi:10.1016/j.micromeso.2009.03.046.

[50] A.M. Lacoste, I.S. Tiscornia, A. V. Boix, CO preferential oxidation on cordierite monoliths coated with $\mathrm{CuO}-\mathrm{CeO} 2 / \mathrm{SBA}-15$ catalysts. Further insights into the physico-chemical aspects of the catalytic behavior, Int. J. Hydrogen Energy. 43 (2018) 14238-14251. doi:10.1016/j.ijhydene.2018.05.122.

[51] M. Kruk, M. Jaroniec, A. Sayari, Application of large pore MCM-41 molecular sieves to improve pore size analysis using nitrogen adsorption measurements, Langmuir. 13 (1997) 6267-6273. doi:10.1021/la970776m.

[52] J. Landers, G.Y. Gor, A. V. Neimark, Density functional theory methods for characterization of porous materials, Colloids Surfaces A Physicochem. Eng. Asp. 437 (2013) 3-32. doi:10.1016/j.colsurfa.2013.01.007.

[53] T. Benamor, L. Vidal, B. Lebeau, C. Marichal, Influence of synthesis parameters on the physico-chemical characteristics of SBA-15 type ordered mesoporous silica, Microporous Mesoporous Mater. 153 (2012) 100-114. doi:10.1016/j.micromeso.2011.12.016.

[54] F. Kleitz, T. Kim, R. Ryoo, Phase Domain of the Cubic Im $3 \mathrm{~h} \mathrm{~m}$ Mesoporous Silica in the, Langmuir. 22 (2006) 440-445.

[55] K.P. De Jong, ed., Synthesis of Solid Catalysts, First, Wiley-VCH, Weinheim, 2009.

[56] F. Rouquerol, J. Rouquerol, K.S.W. Sing, P. Llewellyn, G. Maurin, Adsorption by Powders and Porous Solids, second ed., Elsevier, Amsterdam, 2014. doi:10.1016/B978-0-08-0970356.00007-3.

[57] M.E. Adrover, M. Pedernera, M. Bonne, B. Lebeau, V. Bucalá, L. Gallo, Synthesis and characterization of mesoporous SBA-15 and SBA-16 as carriers to improve albendazole dissolution rate, Saudi Pharm. J. 28 (2020) 15-24. doi:10.1016/j.jsps.2019.11.002.

[58] T. Aumond, L. Pinard, C. Batiot-dupeyrat, A. Sachse, Non-thermal plasma: A fast and efficient template removal approach allowing for new insights to the SBA-15 structure, Microporous Mesoporous Mater. 296 (2020) 110015. doi:10.1016/j.micromeso.2020.110015.

[59] A. Wróblewska, E. Makuch, M. Retajczyk, J. Sreńscek-Nazzal, Z.C. Koren, B. Michalkiewicz, Synthesis, characterization and application of the SBA-16 catalyst modified with titanium(IV) chloride in the eugenol isomerization, Microporous Mesoporous Mater. 311 (2021) 1106885. doi:10.1016/j.micromeso.2020.110685.

[60] S. Madadi, L. Charbonneau, J.-Y. Bergeron, S. Kaliaguine, Aerobic epoxidation of limonene 
using cobalt substituted mesoporous SBA-16 Part 1: Optimization via Response Surface Methodology (RSM), Appl. Catal. B Environ. 260 (2020) 118049.

doi:10.1016/j.apcatb.2019.118049.

[61] J.C. Groen, J. Pérez-Ramírez, Critical appraisal of mesopore characterization by adsorption analysis, Appl. Catal. A Gen. 268 (2004) 121-125. doi:10.1016/j.apcata.2004.03.031.

[62] D. Zhao, Y. Wan, W. Zhou, Structural Characterization Methods, in: Ordered Mesoporous Mater., First, John Wiley \& Sons, Ltd, 2013: pp. 117-151. doi:10.1002/9783527647866.ch4.

[63] F. Kleitz, T. Czuryszkiewicz, L.A. Solovyov, M. Lindén, X-ray structural modeling and gas adsorption analysis of cagelike SBA-16 silica mesophases prepared in a F127/butanol/H2O system, Chem. Mater. 18 (2006) 5070-5079. doi:10.1021/cm061534n.

[64] T. Kjellman, X. Xia, V. Alfredsson, A.E. Garcia-bennett, Influence of microporosity in SBA-15 on the release properties of anticancer drug dasatinib, J. Mater. Chem. B Mater. Biol. Med. 2 (2014) 5265-5271. doi:10.1039/C4TB00418C.

[65] R.M. Grudzien, B.E. Grabicka, M. Jaroniec, Adsorption studies of thermal stability of SBA16 mesoporous silicas, Appl. Surf. Sci. 253 (2007) 5660-5665. doi:10.1016/j.apsusc.2006.12.033.

[66] L.E. Gómez, E.E. Miró, A. V. Boix, Spectroscopic characterization of Mn-Co-Ce mixed oxides, active catalysts for COPROX reaction, Int. J. Hydrogen Energy. 38 (2013) 56455654. doi:10.1016/j.ijhydene.2013.03.004.

[67] F. Larachi, J. Pierre, A. Adnot, A. Bernis, Ce 3d XPS study of composite Ce Mn1-xO2-y wet oxidation catalysts, Appl. Surf. Sci. 195 (2002) 236-250.

[68] A. Naumkin, A. Kraut-Vaas, S.W. Gaarenstroom, C.J. Powell, NIST X-ray Photoelectron Spectroscopy Database, (2012). doi:http://dx.doi.org/10.18434/T4T88K.

[69] J. Lu, J. Wang, Q. Zou, D. He, L. Zhang, Z. Xu, S. He, Y. Luo, Unravelling the Nature of the Active Species as well as the Doping Effect over $\mathrm{Cu} / \mathrm{Ce}$-Based Catalyst for Carbon Monoxide Preferential Oxidation, ACS Catal. 9 (2019) 2177-2195. doi:10.1021/acscatal.8b04035.

[70] J.A. Cecilia, A. Arango-Díaz, F. Franco, J. Jiménez-Jiménez, L. Storaro, E. Moretti, E. Rodríguez-Castellón, $\mathrm{CuO}-\mathrm{CeO} 2$ supported on montmorillonite-derived porous clay heterostructures $(\mathrm{PCH})$ for preferential $\mathrm{CO}$ oxidation in H2-rich stream, Catal. Today. 253 (2015) 126-136. doi:10.1016/j.cattod.2015.01.040.

[71] Á. Szegedi, M. Popova, K. Lázár, S. Klébert, E. Drotár, Impact of silica structure of copper and iron-containing SBA-15 and SBA-16 materials on toluene oxidation, Microporous Mesoporous Mater. 177 (2013) 97-104. doi:10.1016/j.micromeso.2013.04.024. 
[72] F. Wang, R. Büchel, A. Savitsky, M. Zalibera, D. Widmann, S.E. Pratsinis, W. Lubitz, F. Schüth, In Situ EPR Study of the Redox Properties of $\mathrm{CuO}-\mathrm{CeO} 2$ Catalysts for Preferential CO Oxidation (PROX), ACS Catal. 6 (2016) 3520-3530. doi:10.1021/acscatal.6b00589. 
Table 1. Morphology and textural properties of supports and catalysts.

\begin{tabular}{|c|c|c|c|c|c|c|}
\hline $\begin{array}{l}\text { Supports } \\
\text { and } \\
\text { catalysts }\end{array}$ & Morphology & $\begin{array}{l}\text { Impregnation } \\
\text { method }\end{array}$ & $\begin{array}{l}\text { BET Specific } \\
\text { surface area } \\
\left(\mathbf{m}^{2} \mathbf{g}^{-1}\right)\end{array}$ & $\begin{array}{l}\text { Total pore } \\
\text { volume } \\
\left(\mathrm{cm}^{3} \mathrm{~g}^{-1}\right)\end{array}$ & $\begin{array}{l}\text { Pore size } \\
\text { BJH-KJS } \\
(\mathbf{n m})\end{array}$ & $\begin{array}{l}\text { Pore size } \\
\text { DFT }^{\mathbf{c}} \\
(\mathbf{n m})\end{array}$ \\
\hline $15-\mathrm{F}$ & Fibers & - & 650 & 0.70 & 8.2 & 9.2 \\
\hline $15-\mathrm{R}$ & Rods & - & 570 & 0.70 & 6.7 & 7.8 \\
\hline $16-S$ & Spheres & - & 680 & 0.53 & 6.0 & 6.7 \\
\hline $16-I$ & Irregular & - & 650 & 0.45 & 6.2 & 6.9 \\
\hline 15-F/WI & Fibers & Inc. Wetness & 430 & 0.52 & 7.5 & 8.3 \\
\hline 15-F/BM & Fibers & Ball Milling & 401 & 0.47 & 7.9 & 8.9 \\
\hline $15-\mathrm{R} / \mathrm{WI}$ & Rods & Inc. Wetness & 314 & 0.39 & 6.7 & 7.7 \\
\hline $15-\mathrm{R} / \mathrm{BM}$ & Rods & Ball Milling & 406 & 0.36 & 6.9 & 7.9 \\
\hline 16-S/WI & Spheres & Inc. Wetness & 350 & 0.23 & 5.8 & 6.7 \\
\hline 16-S/BM & Spheres & Ball Milling & 343 & 0.22 & 5.1 & 5.3 \\
\hline 16-I/WI & Irregular & Inc. Wetness & 300 & 0.21 & $6.5,7$ & $7.1,7.8$ \\
\hline
\end{tabular}

${ }^{a}$ Total pore volume at $P / P^{0}=0.97$

${ }^{b}$ Maximum in the pore size distribution from BJH-KJS method

${ }^{c}$ Maximum in the pore size distribution from DFT model 
Table 2. Small-angle X-ray scattering data of selected catalysts.

\begin{tabular}{lcccc}
\hline Catalysts & planes & $\mathbf{q}(\mathbf{n m})$ & d-spacing $^{\mathrm{a}}(\mathbf{n m})$ & $\mathbf{a}_{\mathbf{0}}(\mathbf{n m})$ \\
\hline \multirow{3}{*}{$15-\mathrm{F} / \mathrm{BM}$} & $(100)$ & 0.64 & 9.8 & $11.3^{\mathrm{b}}$ \\
& $(110)$ & 1.11 & 5.7 & \\
& $(200)$ & 1.34 & 4.5 & \\
\hline \multirow{3}{*}{$15-\mathrm{R} / \mathrm{BM}$} & $(100)$ & 0.71 & 8.9 & $10.2^{\mathrm{b}}$ \\
& $(110)$ & 1.27 & 4.9 & \\
& $(200)$ & 1.43 & 4.4 & \\
\hline \multirow{3}{*}{$16-\mathrm{S} / \mathrm{BM}$} & $(110)$ & 0.63 & 10.0 & $14.1^{\mathrm{c}}$ \\
& $(200)$ & 0.89 & 7.1 & $14.1^{\mathrm{d}}$ \\
& $(211)$ & 1.10 & 5.7 & \\
\hline
\end{tabular}

a $d$-spacings were calculated from the basic Bragg's law equation

${ }^{b} a_{0}=\left(2 / 3^{1 / 2}\right) d_{100}$

${ }^{c} a_{0}=2^{1 / 2} d_{110}$

${ }^{d} a_{0}=2 d_{200}[62]$ 
Table 3. XPS data and mean $\mathrm{CuO}-\mathrm{CeO}_{2}$ nanoparticle size of catalysts.

\begin{tabular}{|c|c|c|c|c|c|c|c|c|}
\hline \multirow{2}{*}{ Catalysts } & \multirow{2}{*}{$\begin{array}{c}\text { Cryst. } \\
\text { size }^{\mathrm{a}} \\
(\mathbf{n m})\end{array}$} & \multirow{2}{*}{$\begin{array}{l}\text { Part. } \\
\text { size } \\
(\mathbf{n m})\end{array}$} & \multirow{2}{*}{$\mathbf{I}_{\mathbf{u}}, ", \mathbf{I}_{\mathbf{C e ~ t o t}}$} & \multicolumn{3}{|c|}{$\begin{array}{c}\text { B. E. Cu } 2 p_{3 / 2} \\
(\text { fwhm)/eV }\end{array}$} & \multirow{2}{*}{$\% \mathrm{Cu}^{+}$} & \multirow{2}{*}{$\begin{array}{r}\mathrm{Cu} / \mathrm{Ce}^{\mathrm{c}} \\
(\mathbf{0 . 5 5})\end{array}$} \\
\hline & & & & $\mathbf{C u}^{+}$ & $\mathrm{Cu}^{2+}$ & Sat. & & \\
\hline 15-F/WI & 4.9 & $7.4 \pm 2.4$ & 0.13 & $\begin{array}{l}932.9 \\
(3.3)\end{array}$ & $\begin{array}{c}933.8 \\
(4.0)\end{array}$ & $\begin{array}{l}942.7 \\
(5.8)\end{array}$ & 78 & 0.63 \\
\hline $15-\mathrm{F} / \mathrm{BM}$ & 5.0 & $5.7 \pm 1.8$ & 0.14 & $\begin{array}{c}933.1 \\
(3.1)\end{array}$ & $\begin{array}{c}935.3 \\
(2.9)\end{array}$ & $\begin{array}{l}943.0 \\
(4.2)\end{array}$ & 77 & 0.82 \\
\hline 15-R/WI & 5.9 & $8.0 \pm 2.2$ & 0.14 & $\begin{array}{l}932.9 \\
(2.2)\end{array}$ & $\begin{array}{l}934.4 \\
(3.2)\end{array}$ & $\begin{array}{l}943.7 \\
(5.3)\end{array}$ & 49 & 0.55 \\
\hline $15-\mathrm{R} / \mathrm{BM}$ & 5.4 & $3.9 \pm 1.1$ & 0.13 & $\begin{array}{l}933.0 \\
(3.0)\end{array}$ & $\begin{array}{c}935.3 \\
(2.8)\end{array}$ & $\begin{array}{l}943.2 \\
(3.6)\end{array}$ & 74 & 0.77 \\
\hline 16-S/WI & 5.4 & $5.7 \pm 1.3$ & 0.14 & $\begin{array}{c}932.9 \\
(4.1)\end{array}$ & $\begin{array}{l}934.6 \\
(3.2)\end{array}$ & $\begin{array}{l}942.1 \\
(6.0)\end{array}$ & 33 & 0.30 \\
\hline 16-S/BM & 5.1 & $5.3 \pm 1.1$ & 0.14 & $\begin{array}{l}932.8 \\
(2.8)\end{array}$ & $\begin{array}{l}934.6 \\
(3.8)\end{array}$ & $\begin{array}{c}942.9 \\
(4.2)\end{array}$ & 37 & 1.22 \\
\hline 16-I/WI & 5.1 & $6.4 \pm 1.0$ & 0.12 & $\begin{array}{l}933.0 \\
(2.8)\end{array}$ & $\begin{array}{l}935.0 \\
(3.0)\end{array}$ & $\begin{array}{l}943.2 \\
(7.2)\end{array}$ & 78 & 0.65 \\
\hline $\begin{array}{l}\mathrm{Cu}-\mathrm{SBA}- \\
15\end{array}$ & - & - & - & $\begin{array}{c}933.2 \\
(1.8)\end{array}$ & $\begin{array}{l}934.1 \\
(2.3)\end{array}$ & $\begin{array}{c}943.7 \\
(5.8)\end{array}$ & 25 & - \\
\hline
\end{tabular}

${ }^{a}$ Crystallite size of $\mathrm{CeO}_{2}$ was estimated by Scherrer's equation from more intense diffraction peak, (111) plane of $\mathrm{CeO}_{2}$ phase (see Fig. 8)

${ }^{b}$ Mean particles size of $\mathrm{CuO}-\mathrm{CeO}_{2}$ measured from TEM images (see Fig. 5 and Fig. S2 supplementary materials)

${ }^{c}$ Surface atomic ratio, calculated considering $\mathrm{Cu}\left(2 p_{3 / 2}\right), \mathrm{Ce}\left(3 d_{5 / 2}\right)$ and Si $2 p$ regions, in brackets nominal ratio 
Figure 1. SEM images of the SBA- mesoporous supports (A) 15-F, (B) 15-R, (C) 16-I, (D) $16-\mathrm{S}$.

Figure 2. SEM micrographs of (A) 15-F/WI, (B) 15-F/BM, (C) 15-R/WI and (D) 15-R/BM catalysts.

Figure 3. SEM image (A) and EDS mapping (B-E) of 15-F/WI catalyst. (B) $\mathrm{Cu},(\mathrm{C}) \mathrm{Ce}$, (D) Si and (E) O. Molar fraction $\mathrm{Si} / \mathrm{Ce} / \mathrm{Cu}=0.88 / 0.071 / 0.048$.

Figure 4. SEM images and EDS mapping of $\mathrm{Cu}$ and $\mathrm{Ce}$ of 16-S/WI (A, B, C) and 16-S/BM $(\mathrm{D}, \mathrm{E}, \mathrm{F})$ catalysts.

Figure 5. TEM images of selected catalysts (A) 15-F/WI, (B) 15-F/BM, (C) 15-R/BM and (D) 16-S/BM. The inset graphs represent the $\mathrm{CuO}-\mathrm{CeO}_{2}$ particle size distribution.

Figure 6. Nitrogen adsorption-desorption isotherms of as-synthesized supports and catalysts. (A) SBA-15 fibers, (B) SBA-15 rods and (C) SBA-16.

Figure 7. SAXS patterns. (A) 15-F/BM, (B) 15-R/BM and (C) 16-S/BM.

Figure 8. X-ray diffraction of the catalysts.

Figure 9. $\mathrm{Cu} 2 \mathrm{p}_{3 / 2}$ spectra of CuCe catalysts based on SBA-15 (left), on SBA-16 (right).

Figure 10. COPrOx reaction. $\mathrm{CO}$ conversion and $\mathrm{O}_{2}$ to $\mathrm{CO}_{2}$ selectivity. CuCe mesoporous catalysts based on SBA-15 (left), on SBA-16 (right). 
Figure 1

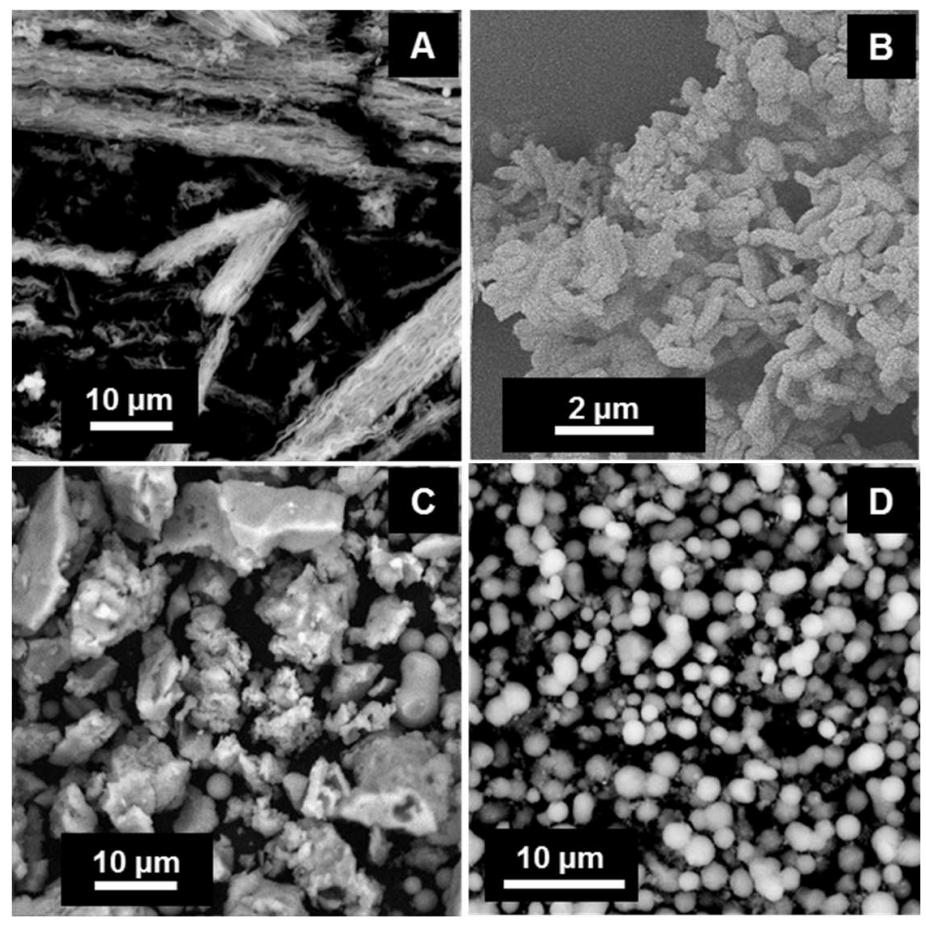


Figure 2
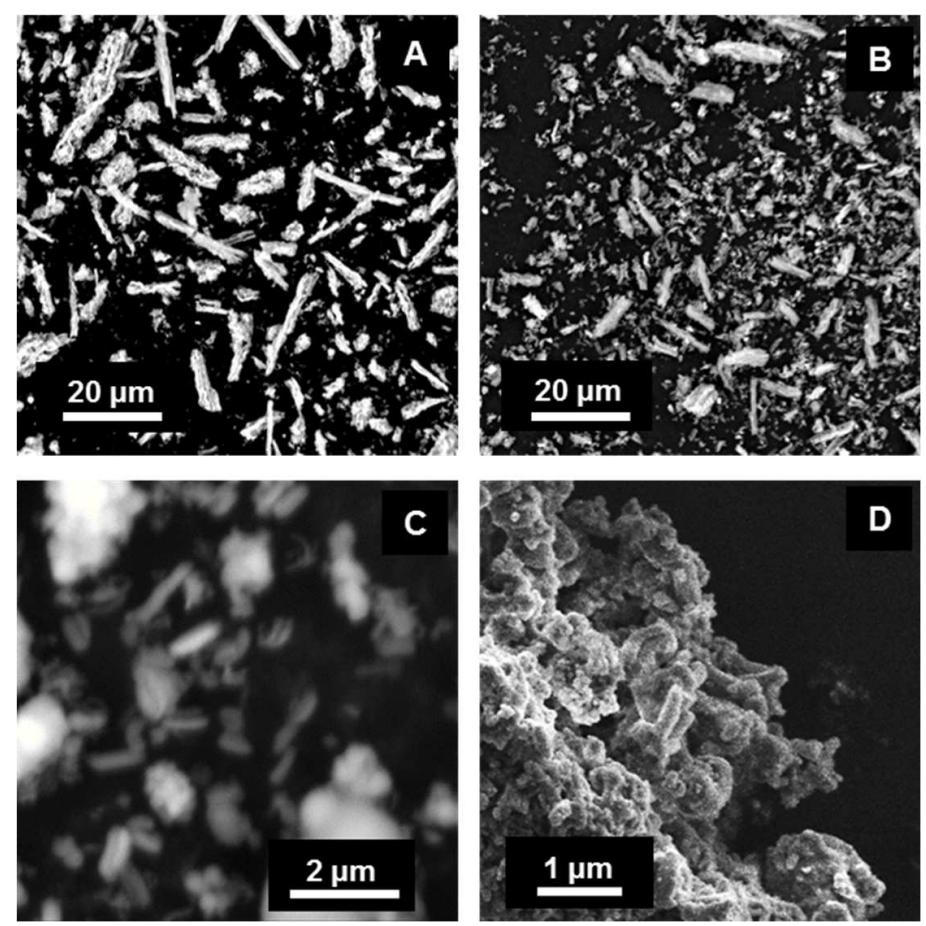
Figure 3
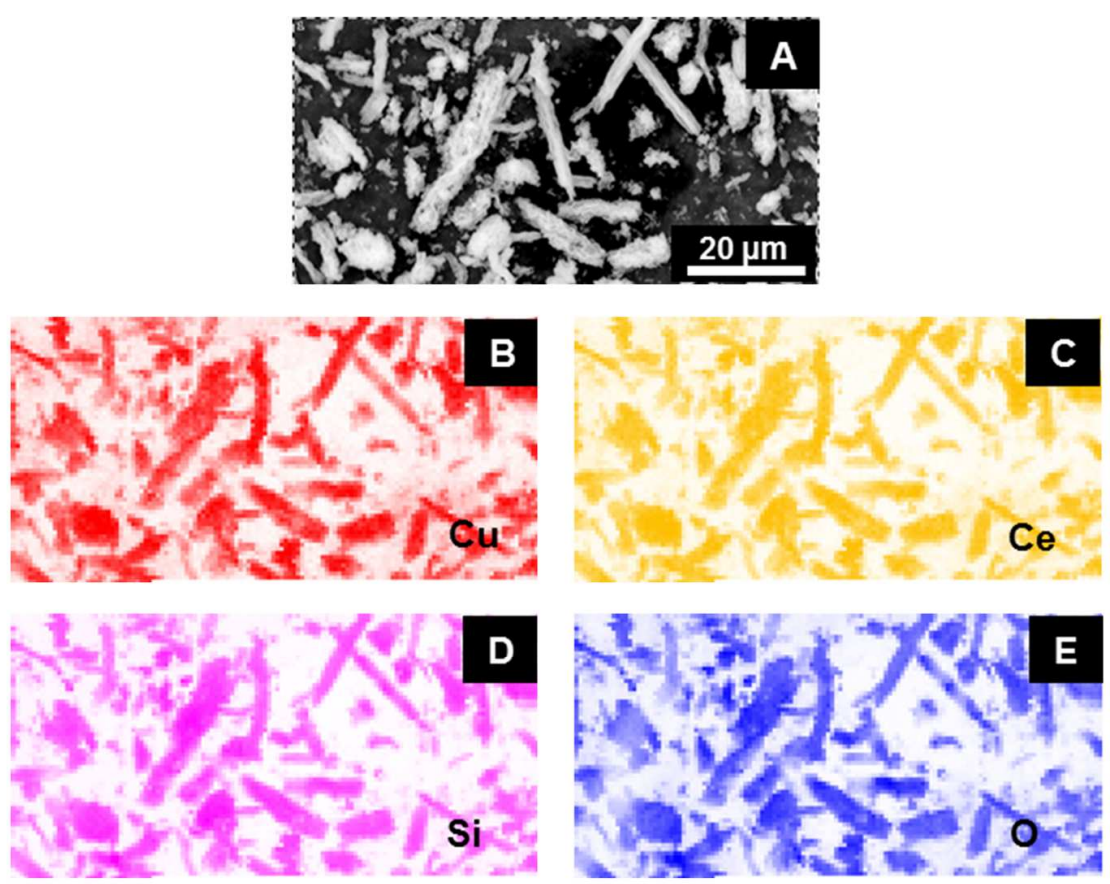
Figure 4
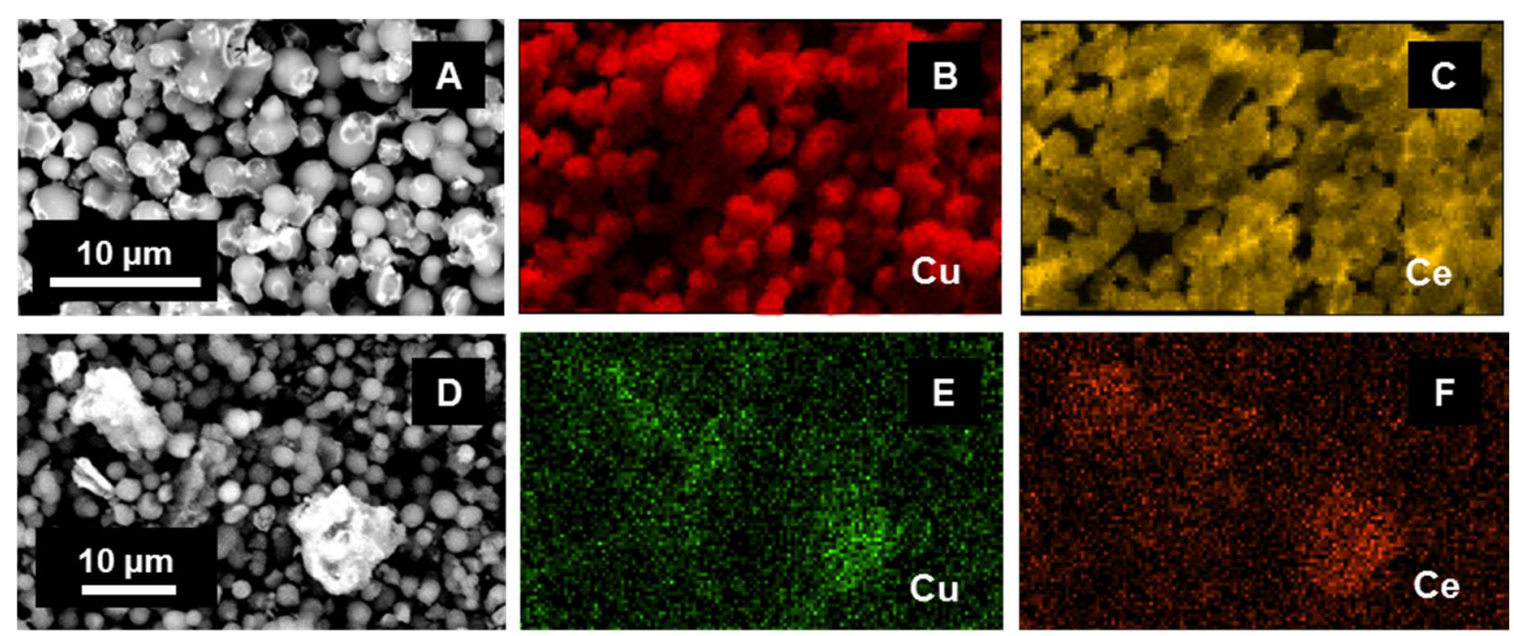
Figure 5
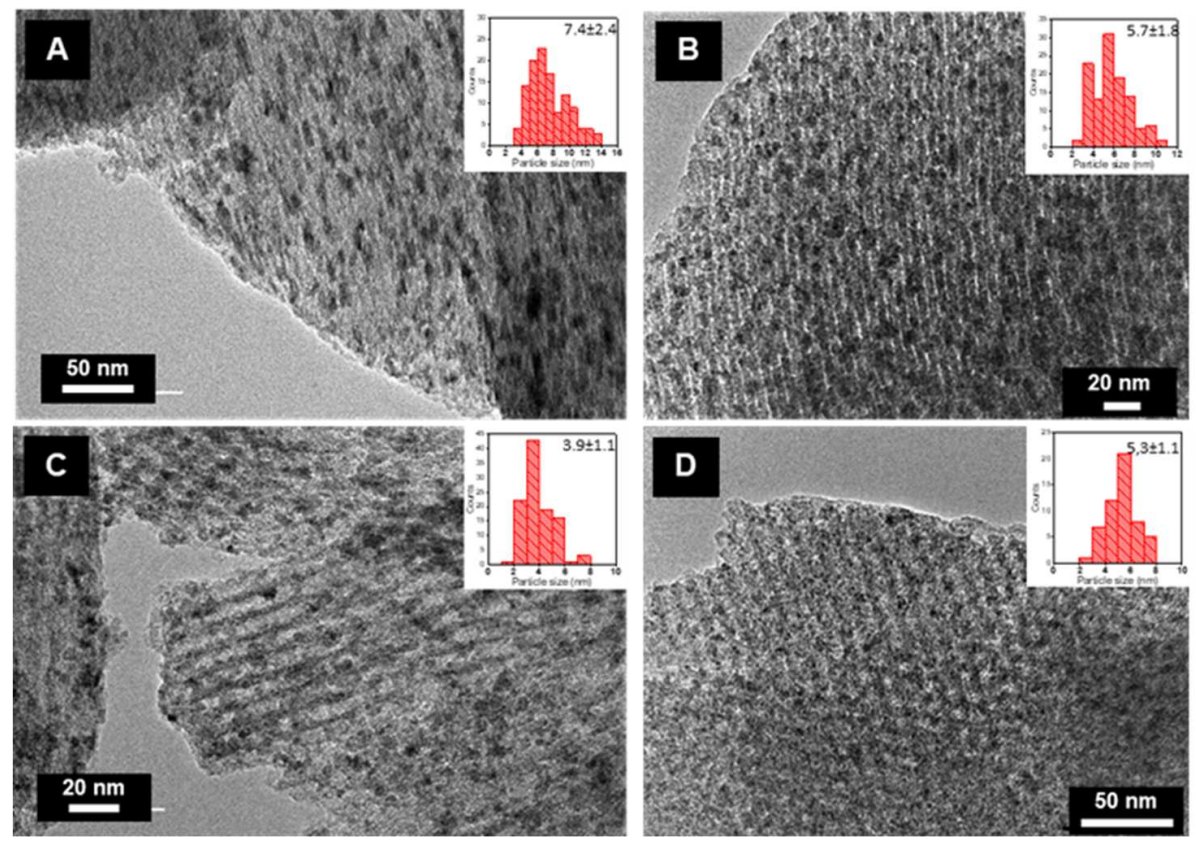
Figure 6
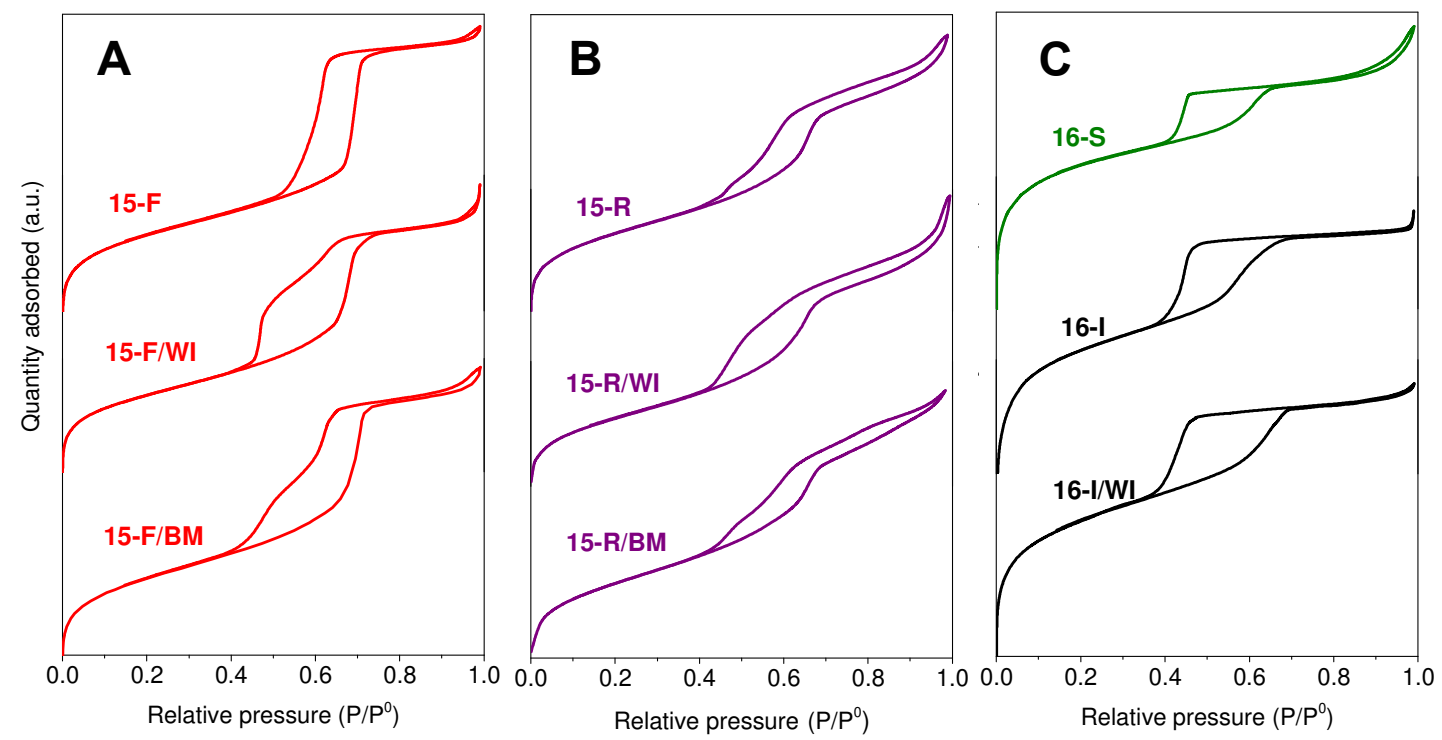
Figure 7
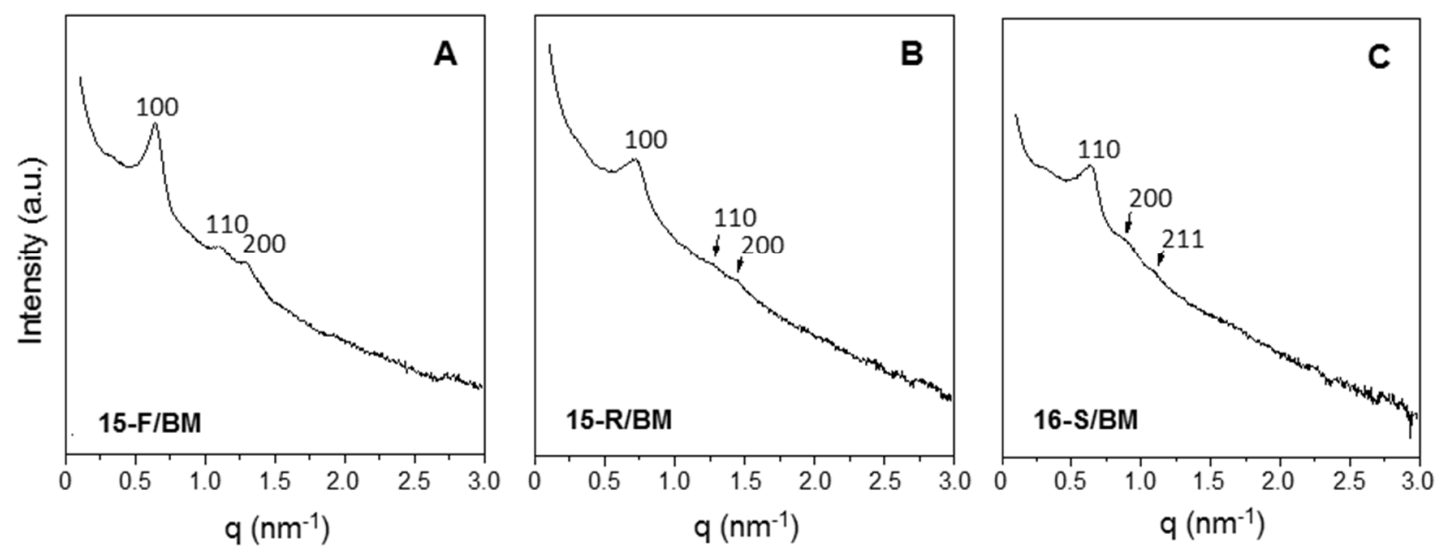
Figure 8

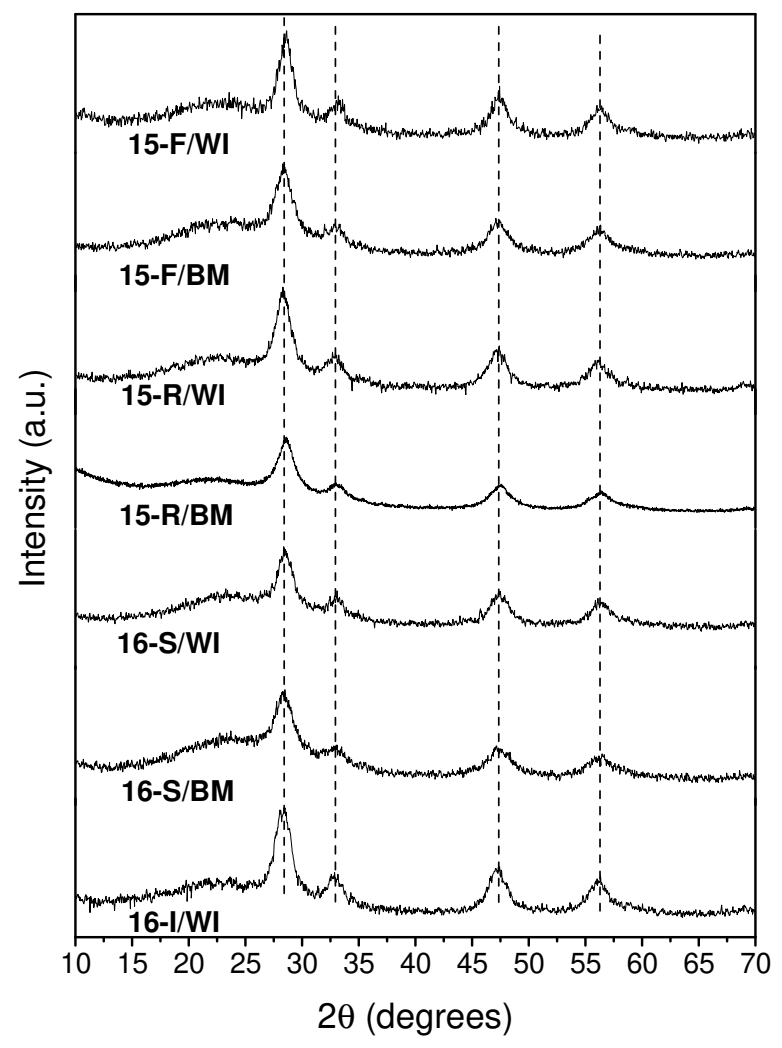


Figure 9
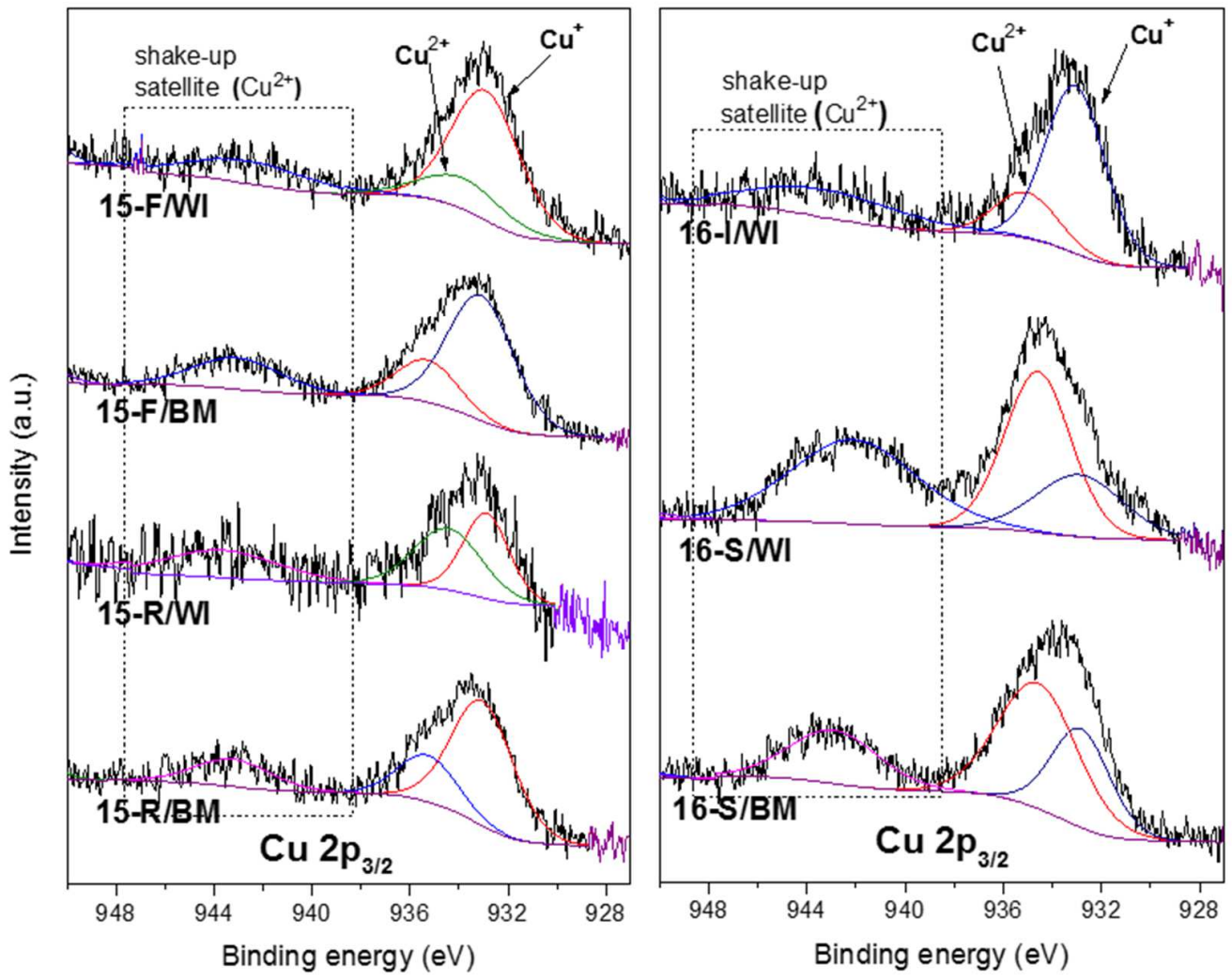
Figure 10
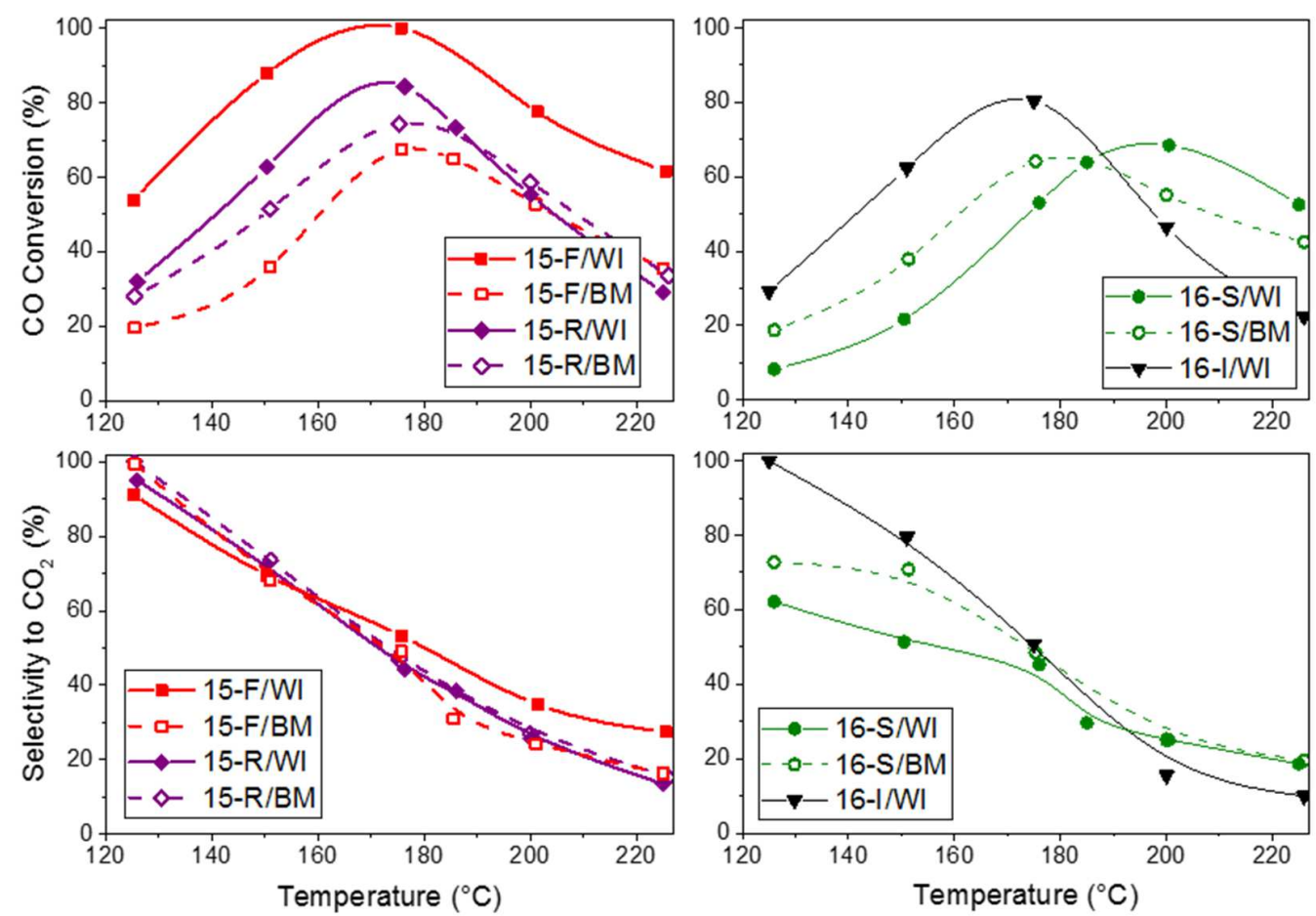